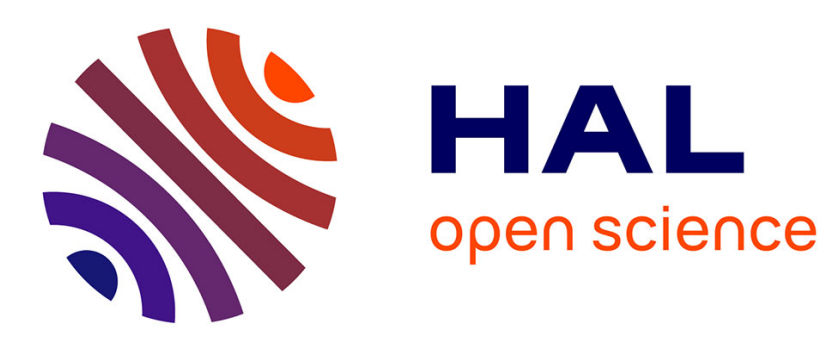

\title{
Rent Creation and Rent Sharing: New Measures and Impacts on Total Factor Productivity
}

\author{
Gilbert Cette, Jimmy Lopez, Jacques Mairesse
}

\section{To cite this version:}

Gilbert Cette, Jimmy Lopez, Jacques Mairesse. Rent Creation and Rent Sharing: New Measures and Impacts on Total Factor Productivity. Economic Inquiry, 2019, 57 (4), pp.1915-1938. 10.1111/ecin.12809 . hal-02279411

\section{HAL Id: hal-02279411 https://hal-amu.archives-ouvertes.fr/hal-02279411}

Submitted on 13 May 2020

HAL is a multi-disciplinary open access archive for the deposit and dissemination of scientific research documents, whether they are published or not. The documents may come from teaching and research institutions in France or abroad, or from public or private research centers.
L'archive ouverte pluridisciplinaire HAL, est destinée au dépôt et à la diffusion de documents scientifiques de niveau recherche, publiés ou non, émanant des établissements d'enseignement et de recherche français ou étrangers, des laboratoires publics ou privés. 


\title{
WORKING

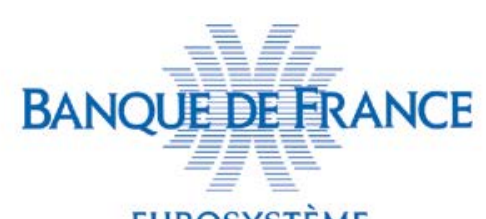 \\ EUROSYSTÈME
} paper

\section{Rent creation and sharing: new measures and impacts on TFP}

\author{
Gilbert Cette ${ }^{1}$, Jimmy Lopez ${ }^{2}$, \\ and Jacques Mairesse ${ }^{3}$
}

April 2018, WP \#674

\begin{abstract}
This analysis proposes new measures of rent creation or (notional) mark-up and workers' share of rents on cross-country-industry panel data. While the usual measures of mark-up rate implicitly assume perfect labor markets, our approach relaxes this assumption, and takes into account that part of firms' rent created in an industry is shared with workers to an extent which can vary with their skills. Our results are based on a cross-country-industry panel covering 14 OECD countries and 19 industries over the 1985-2005 period. In a first part of our analysis we draw on OECD indicators of product and labor market (anticompetitive) regulations to test how they are related to our new measures of mark-up and rent-sharing. We find that anti-competitive Non-Manufacturing Regulations (NMR) affect mark-up rates positively, and hence firms' rent creation and workers' share of rent, whereas Employment Protection Legislation (EPL) has no impact on rent creation, but boosts workers' wages per hour. However, we observe that these wage increases are offset by a negative impact from EPL on hours worked per output unit, leading to a non-significant impact of EPL on workers' share of rents. The effects of EPL for low-skilled workers appear to be more pronounced than those for medium-skilled workers, both being much greater than for highlyskilled workers. In the second part of our analysis, we estimate the impacts of our new measures on Total Factor Productivity (TFP) in the framework of a straightforward regression model. We use the OECD regulations indicators as relevant instrument to take care of endogeneity and to make sure that the resulting estimates assess the proper regulation impacts of rent creation and sharing without being biased by other confounding effects. We find that less competition in the product and labor markets as assessed by our measures of mark-up and workers' share of rents have both substantial negative impacts on TFP.
\end{abstract}

Keywords: product market regulations, labor market regulations, mark-up, rent-sharing, TFP.

JEL classification: E22, E24, O30; L50, O43, O47, C23.

1 Gilbert Cette, Banque de France and Aix-Marseille School of Economics, CNRS \& EHESS, gilbert.cette@,banque-france.fr

2 Jimmy Lopez, Banque de France and Université de Bourgogne (LEDI), jimmy.lopez@u-bourgogne.fr

3 Jacques Mairesse, ENSAE (CREST), Maastricht University (UNU-MERIT), Banque de France and NBER, jacques.mairesse@ensae.fr 


\section{NON-TECHNICAL SUMMARY}

Extensive empirical literature based on cross-country-industry panel data has been devoted in recent years to the analysis of the impact of competition on productivity. Many of the papers concerned draw on the OECD's anti-competitive Non-Manufacturing Regulation (NMR) indicators to estimate the productivity impact of the lack of competition in product markets. A few papers have also used the OECD's Employment Protection Legislation (EPL) indicators to gauge the productivity impact of the lack of competition or flexibility in labor markets. In the present study, we propose new measures of rent creation or (notional) mark-up and workers' share of rents on cross-country-industry panel data to estimate both types of productivity impacts and use the OECD regulations indicators as relevant instrument to take care of endogeneity and to make sure that the resulting estimates assess the proper impacts of regulations without being biased by other confounding effects. ${ }^{4}$

In Blanchard and Giavazzi's (2003) theoretical approach, the creation of rents results from product market regulations, while workers' rent-sharing is influenced by labor market regulations. The analysis of Spector (2004), which is also theoretical, leads to the same conclusions: a decrease in the barriers to entry reduces the rent to share between capital and labor and thus impacts real wages negatively. These models have received empirical corroboration on a cross-country-industry panel by Askenazy, Cette and Maarek (2018), who use value-added prices and the value-added labor shares as indicators of rent and rent-sharing. The empirical investigation of Azmat, Manning and Van Reenen (2012) has also shown, on a cross-country-industry panel, that different components of the OECD NMR indicator have contrasting impacts on labor shares. They find a positive influence of the 'state control' component (a combination of sub-indicators on government ownership, control and interference in the running of the industry) and a negative influence of barriers to entry on labor shares. These findings may reflect the fact that barriers to entry tend mainly to augment total rents, while `state control' increases workers' bargaining power and their share of rents.

Our present paper follows on from Cette, Lopez and Mairesse (2016a), not only because we exploit the same cross-country-industry panel covering 14 OECD countries and 19 industries over the 1985-2005 period, but also because we follow a similar, but direct and a priori preferable approach. In our previous paper, we first used industry production prices and wages as very crude indicators of mark-ups and workers' rent-sharing, and we then instrumented these indicators with the NMR and EPL indicators to evaluate the impacts of product and labor market regulation on productivity. This is what we do here, but on the basis of the new measures of mark-up rates and workers' rent shares that we propose.

We first explain the new measures of mark-up and workers' rent-sharing at the country-industry level, which are largely inspired by the firm panel data analyses of Dobbelaere and Mairesse (2013, 2015, 2017). We then assess the relationship of these new measures with the OECD NMR and EPL regulation indicators. Finally, using the OECD indicators as instrumental variables, we assess the impacts on total factor productivity (TFP) of mark-up and workers' share of rents. While standard measures of firms' market power, such as the Lerner index, assume perfect labor markets, our new measures relax this assumption by taking into account that workers may appropriate part of the rent created in a given industry. To give a preview of our results, we find that our new measures lead to a more in-depth understanding of the impacts of regulations that overall corroborates Blanchard and Giavazzi's (2003) theoretical conclusions, but with interesting differences.

Concerning the relationship of the OECD indicators with our measures, we find that: (i) NMR is positively linked with the mark-up and workers' share of rents, a result which is consistent with Jean and Nicoletti's (2015) estimates of increasing inter-industry wage differentials; (ii) EPL has a negative impact on hours worked per output unit, which offsets an increase in workers' rent per

4 There are several papers that investigate the relationship between regulations and other measures of competition, but no cross-country-industry analysis of the impact of NMR or EPL indicators on direct measures of competition. 
hour and leads to a non-significant impact of EPL on workers' share of rents; iii) EPL has a positive impact on the wage per hour of low- and medium-skilled workers positively, but a negative one on their hours worked per output unit, particularly for low-skilled workers, thus also on their share of rent, whereas highly-skilled workers tend to be much less affected. Regarding the impacts on TFP, we find that lack of competition on the product market and of flexibility on the labor market have a detrimental impact on TFP, which is consistent with Cette, Lopez and Mairesse (2016a) and the previous literature.

Using our estimation results to calibrate an illustrative out-of-sample policy simulation, we show that a decrease in mark-up rates and workers' bargaining power that would result from a switch of countries' NMR to the lowest NMR levels might lead to an average increase in TFP of $3.7 \%$ in the long run. But the adoption of these levels of lowest regulation would require very large-scale product market structural reforms in some countries, such as France and Italy. The implementation of such reforms cannot be considered politically or socially realistic in the short to medium term.

The original findings of this paper give more content to the channels of the impact of market (both product and labor) regulation on the rent-building and rent-sharing processes. They also confirm that the impact of regulations on productivity occurs via lack of competition and labor market flexibility. A limitation of our investigation concerns the distinction between short- and long-run effects. Our estimation results using static specifications may be interpreted as long-run estimates, but short-run changes are important in understanding the mechanisms for and political feasibility of reforms. The use of a dynamic approach, such as an Error Correction Model, would be interesting but hard to implement because of the lack of time variability in our regulation indicators, particularly the EPL indicator. We are probably at the limit of the use of a cross-country-industry panel dataset, and some corroboration may be needed, perhaps from firm-level data.

\section{TFP gains from a switch to the lowest levels of NMR}

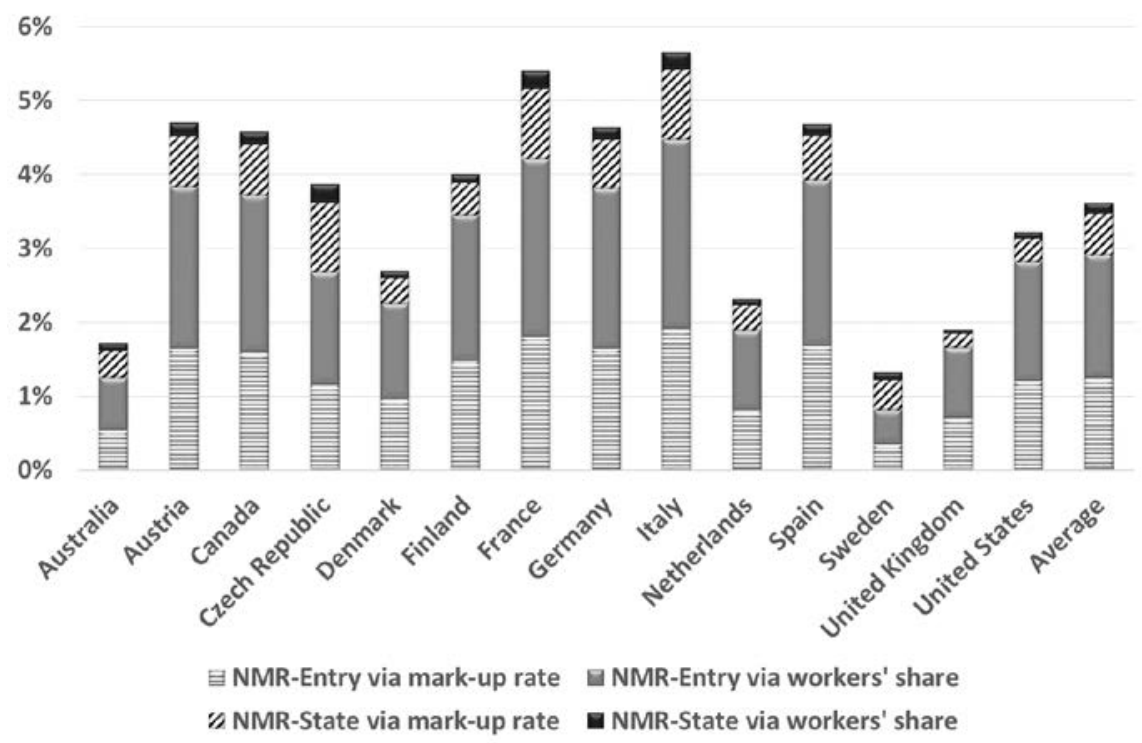

This Graph uses our estimation results to calibrate an illustrative out-of-sample policy simulation. It shows the TFP impact that would come from a decrease in mark-up rates and workers' bargaining power resulting from a switch of countries' NMR to the lowest NMR levels.

In average over the 14 countries of our dataset, this switch would imply an increase of the TFP at the country level by $3.7 \%$. This would come from the decrease of the State control and of the barriers to entry, through the decrease of producer rents and worker bargaining power. 


\title{
Création et partage des rentes : nouvelles mesures et effets sur la PGF
}

\begin{abstract}
RÉSUMÉ
Cette analyse propose de nouvelles mesures de la rente du producteur et de son partage entre entreprises et travailleurs, sur un panel de données pays-secteur. Alors que les mesures habituelles par le taux de marge supposent implicitement un marché du travail parfait, notre approche relâche cette hypothèse en tenant compte, par niveau d'éducation, de la part de la rente que les travailleurs peuvent s'approprier. Ces nouvelles mesures sont construites pour un panel de 14 pays, 19 secteurs sur la période 1985-2005. Nous étudions d'abord les relations entre la rente et les indicateurs OCDE sur les réglementations anticoncurrentielles des secteurs non-manufacturiers (NMR) et sur les régulations issues de la législation protectrice de l'emploi (EPL). D'après nos résultats d'estimations, une augmentation des NMR induirait un accroissement de la rente du producteur, ainsi que de la part de cette rente appropriée par les travailleurs. C'est particulièrement le cas pour les réglementations concernant les barrières à l'entrée. En revanche, une augmentation d'EPL n'aurait pas d'effet sur la rente appropriée par les travailleurs. En effet, elle accroitrait le salaire horaire mais cet accroissement salarial serait compensé par une baisse du nombre d'heures travaillées par unité produite. Ainsi, EPL n'affecterait pas le partage de la rente. Ces effets d'EPL seraient d'autant plus forts que les travailleurs sont peu qualifiés. Nous étudions ensuite les effets de nos nouvelles mesures de la rente sur la productivité globale des facteurs. Les indicateurs OCDE servent alors d'instruments afin de tenir compte de l'endogénéité de ces mesures et de s'assurer que les résultats d'estimations indiquent bien les effets de la concurrence et de la négociation salariale sur la productivité. Nous observons alors qu'une baisse de la concurrence ou un renforcement du pouvoir de négociation des travailleurs auraient un impact négatif sur la productivité.
\end{abstract}

Mots-clés : régulations du marché des biens; régulations du marché du travail ; mark-up; partage des rentes; PGF

Les Documents de travail reflètent les idées personnelles de leurs auteurs et n'expriment pas nécessairement la position de la Banque de France. Ils sont disponibles sur publications.banque-france.fr 


\section{INTRODUCTION}

Extensive empirical literature based on cross-country-industry panel data has been devoted 1papers concerned draw on the OECD's anti-competitive Non-Manufacturing Regulation (NMR) indicators to estimate the productivity impact of the lack of competition in product markets (see, for instance, Conway et al., 2006, and Barone and Cingano, 2011). A few papers have also used the OECD's Employment Protection Legislation (EPL) indicators to gauge the productivity impact of the lack of competition or flexibility in labor markets (see, for instance, Bassanini, Nunziata and Venn, 2009). In the present study, we propose new measures of rent creation or (notional) mark-up and workers' share of rents on crosscountry-industry panel data to estimate both types of productivity impacts and use the OECD regulations indicators as relevant instrument to take care of endogeneity and to make sure that the resulting estimates assess the proper impacts of regulations without being biased by other confounding effects. ${ }^{5}$

In Blanchard and Giavazzi's (2003) theoretical approach, the creation of rents results from product market regulations, while workers' rent-sharing is influenced by labor market regulations. The analysis of Spector (2004), which is also theoretical, leads to the same conclusions: a decrease in the barriers to entry reduces the rent to share between capital and labor and thus impacts real wages negatively. These models have received empirical corroboration on a cross-country-industry panel by Askenazy, Cette and Maarek (2018), who use value-added prices and the value-added labor shares as indicators of rent and rentsharing. The empirical investigation of Azmat, Manning and Van Reenen (2012) has also shown, on a cross-country-industry panel, that different components of the OECD NMR indicator have contrasting impacts on labor shares. They find a positive influence of the 'state control' component (a combination of sub-indicators on government ownership, control and interference in the running of the industry) and a negative influence of barriers to entry on labor shares. These findings may reflect the fact that barriers to entry tend mainly to augment total rents, while `state control' increases workers' bargaining power and their share of rents.

Our present paper follows on from Cette, Lopez and Mairesse (2016a), not only because we exploit the same cross-country-industry panel covering 14 OECD countries and 19 industries over the 1985-2005 period, but also because we follow a similar, but direct and $a$ priori preferable approach. In our previous paper, we first used industry production prices and wages as very crude indicators of mark-ups and workers' rent-sharing, and we then instrumented these indicators with the NMR and EPL indicators to evaluate the impacts of product and labor market regulation on productivity. This is what we do here, but on the basis of the new measures of mark-up rates and workers' rent shares that we propose.

In a nutshell in this paper, we will first explain the new measures of mark-up and workers' rent-sharing at the country-industry level, which are largely inspired by the firm panel data analyses of Dobbelaere and Mairesse (2013, 2015, 2017). We will then assess the

5 There are several papers that investigate the relationship between regulations and other measures of competition, but no cross-country-industry analysis of the impact of NMR or EPL indicators on direct measures of competition. For instance, Griffith, Harrison and Simpsons (2010) use regulation indicators as instruments to estimate the impact of a direct measure of competition, average profitability, on productivity growth. But their regulation indicators concern non-tariff barriers to trade and other barriers to the free movement of production factors across borders. It is also interesting to note that Nicoletti and Pryor (2006) study the relationship between 'objective' and 'subjective' measures of competition, the first based on an extensive review of laws and regulations, and the second on observational data of those familiar with these regulations. Both papers show correlations between regulations and other measures of competition. 
relationship of these new measures with the OECD NMR and EPL regulation indicators. Finally, using the OECD indicators as instrumental variables, we will assess the impacts on total factor productivity (TFP) of mark-up and workers' share of rents. While standard measures of firms' market power, such as the Lerner index, assume perfect labor markets, our new measures relax this assumption by taking into account that workers may appropriate part of the rent created in a given industry. To give a preview of our results, we find that our new measures lead to a more in-depth understanding of the impacts of regulations that overall corroborates Blanchard and Giavazzi's (2003) theoretical conclusions, but with interesting differences.

Concerning the relationship of the OECD indicators with our measures, we find that: (i) NMR is positively linked with the mark-up and workers' share of rents, a result which is consistent with Jean and Nicoletti's (2015) estimates of increasing inter-industry wage differentials; (ii) EPL has a negative impact on hours worked per output unit, which offsets an increase in workers' rent per hour and leads to a non-significant impact of EPL on workers' share of rents; iii) EPL has a positive impact on the wage per hour of low- and medium-skilled workers positively, but a negative one on their hours worked per output unit, particularly for low-skilled workers, thus also on their share of rent, whereas highlyskilled workers tend to be much less affected. Regarding the impacts on TFP, we find that lack of competition on the product market and of flexibility on the labor market have a detrimental impact on TFP, which is consistent with Cette, Lopez and Mairesse (2016a) and the previous literature. Using our estimation results to calibrate an illustrative out-ofsample policy simulation, we find that a decrease in country regulations to the lowest NMR levels in 2013 (the last year available for the regulation indicators) might lead in the long run to an overall average country rise in TFP of about $3.7 \%$.

In Section 2, we explain our measures of the mark-up rate and workers' share of rents and comment on a number of instructive descriptive statistics. In Section 3, we document in detail the relationship between the OECD NMR and EPL indicators and our measures. In Section 4, we explain and discuss the OLS and IV estimated impacts on TFP of our measures. We also present an illustrative policy simulation of the expected effects on TFP of pro-competitive reforms. Section 5 concludes.

\section{MEASURING MARK-UPS AND EXTENT OF RENT-SHARING AT THE INDUSTRY-COUNTRY-LEVEL}

\subsection{DEFINITIONS}

Standard measures of lack of competition / mark-ups, such as the Lerner index, assume implicitly perfect labor markets. In this paper, we consider a measure of markup at the industry level taking into account that workers may capture part of the created rent, and the corresponding measure of workers' share of rents.

Product market imperfections make it possible to set selling prices higher than marginal costs in order to extract a rent (country and time indices are omitted):

$$
P_{i}=\left(1+M U R_{i}\right) C_{i}
$$

where: $P_{i}$ is the relative production price (i.e. the ratio of production price to GDP price) in industry $i ; M U R_{i}$ the mark-up rate; and $C_{i}$ the marginal cost. 
The marginal cost is difficult to measure with our industry-level data. As a proxy, we use the average variable cost per output unit, assuming the capital cost is fixed in the short run. ${ }^{6}$ An original feature of our approach is to consider that workers' wages are the sum of their share of rent and their reservation wages, with only the latter being considered as a cost during wage bargaining. We can thus write:

$$
\begin{gathered}
C_{i}=\frac{\sum_{j}\left[W_{j}^{r} N_{i j}\right]+M_{i}}{Q_{i}}=\frac{W_{i}^{r} N_{i}+M_{i}}{Q_{i}} \\
M U R_{i}=\frac{P_{i}-C_{i}}{C_{i}}=\frac{P_{i} Q_{i}-\left(W_{i}^{r} N_{i}+M_{i}\right)}{W_{i}^{r} N_{i}+M_{i}}
\end{gathered}
$$

where: $W_{j}^{r}$ is the 'reservation wage' per hour at skill level $j ; N_{i j}$ is the number of hours worked in industry $i$ for skill $j$ (low, medium or high skill); $M_{i}$ the intermediate input total cost; and $Q_{i}$ the production at constant prices. ${ }^{7}$ To simplify the following equations, we introduce the variables $W_{i}^{r}$ and $N_{i}$, which are the overall skill average 'reservation wage' and the total number of hours worked.

We are missing information concerning 'reservation wages', but we assume that, for a given country and year, the 'reservation wage' should be equal to or lower than the minimum industry average observed workers' compensation across all industries. Therefore, we measure the 'reservation wage' relative to the country $\mathrm{x}$ year minimum industry average worker compensation for each skill level, with our main measures equal to $90 \%$ of it (our main results are robust to several thresholds). This measure implicitly assumes that all workers are identical, for a given skill level, which is of course a strong assumption. In the same way, the difference between the variable cost per output unit and relative production prices may also stem from innovation, entrepreneurship and workers' efforts, etc. So our measure of the mark-up rate includes not only the rent created by product market imperfections but also the consequences of these various factors. Section 3 sets out how we treat this issue econometrically.

Our measure of workers' bargaining power derives from the Nash bargaining solution, when firms and workers together choose wages and employment level simultaneously. Thus, wages and employment are chosen in order to maximize the average logarithm of firms' and workers' rents:

$$
W S R_{i} \log \left(\left(W_{i}-W_{i}^{r}\right) N_{i}\right)+\left(1-W S R_{i}\right) \log \left(P_{i} Q_{i}-\left(W_{i} N_{i}+M_{i}\right)\right)
$$

where $W S R_{i}$ is workers' bargaining power and $W_{i}$ the average compensation in industry $I$; and the first and second terms respectively correspond to workers' rent and firms' rent. We thus derive that at the maximum, that the workers' bargaining power and their share of rents are equal:

$$
W S R_{i}=\frac{\left(W_{i}-W_{i}^{r}\right) N_{i}}{P_{i} Q_{i}-\left(W_{i}^{r} N_{i}+M_{i}\right)}
$$

6 This assumption is standard but questionable. See Appendix D for "An analysis of sensitivity to capital intensity".

7 Note that $C_{i}$ is not the marginal cost from the firm's point of view. For firms, the cost also includes the rent captured by workers. It is important to calculate the rent created from $C_{i}$ and not from firms' cost perception in order to measure total rent and rent-sharing. 
In order to investigate further the changes in our two key measures $(M U R)$ and $(W S R)$ in the next sections, we consider the two following interesting decompositions. The mark-up rate $(\underline{M U R})$ is equal to the sum of to the sum of the firms' and the workers' rent rates $\left(M U R^{f}\right)$ and $\left(M U R^{l}\right)$ :

$$
M U R_{i}^{f}=\frac{P_{i} Q_{i}-\left(W_{i} N_{i}+M_{i}\right)}{W_{i}^{r} N_{i}+M_{i}} \text { and } M U R_{i}^{l}=\frac{\left(W_{i}-W_{i}^{r}\right) N_{i}}{W_{i}^{r} N_{i}+M_{i}}
$$

where $\left(M U R^{f}\right)$ is a measure of the mark-up rate assuming a perfect labor market. The workers' share of rent can be broken down into three multiplicative components:

$$
\frac{W_{i}-W_{i}^{r}}{P^{G D P}} ; \frac{N_{i}}{Q_{i}} \text { and } \frac{P^{G D P}}{P_{i}-C_{i}}
$$

where $P^{G D P}$ is the GDP price. The first component corresponds to the workers' rent per hour (on average across the different skill levels) deflated by $P^{G D P}$, say at constant prices; the second is the inverse of labor productivity (number of hours worked per output unit) and the third is the inverse of total rent per output unit at constant prices.

\subsection{DESCRIPTIVE ANALYSIS}

To calculate the mark-up rate $(M U R)$ and the workers' share of rent $(W S R)$, we use data from the OECD STAN database concerning production value and prices as well as intermediate input costs, and EU-KLEMS data concerning labor compensation per hour and the number of hours worked for the three skill levels. These measures are calculated for our estimation sample of 4,988 observations covering 14 OECD countries (Australia, Austria, Canada, Czech Republic, Denmark, Finland, France, Germany, Italy, Netherlands, Spain, Sweden and the United States) and 19 industries over the 1985-2005 period (see Section III for more information on the estimation sample). This section sets out the descriptive analysis of these measures (Appendix A provides more detailed data information). 


\section{Chart 1: Mark-up rate and rent-sharing, density}

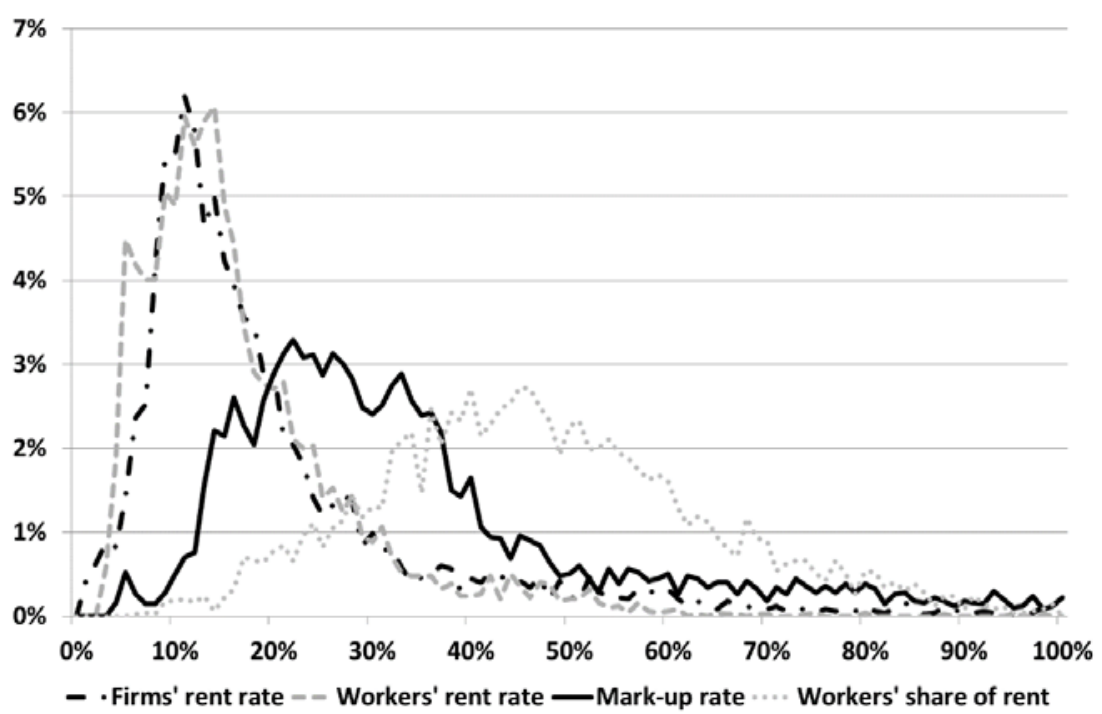

For convenience, the few values higher than or equal to 1 or 0 are excluded from this chart. ${ }^{8}$

\section{Chart 2: Changes in firms' and workers' rent rates}

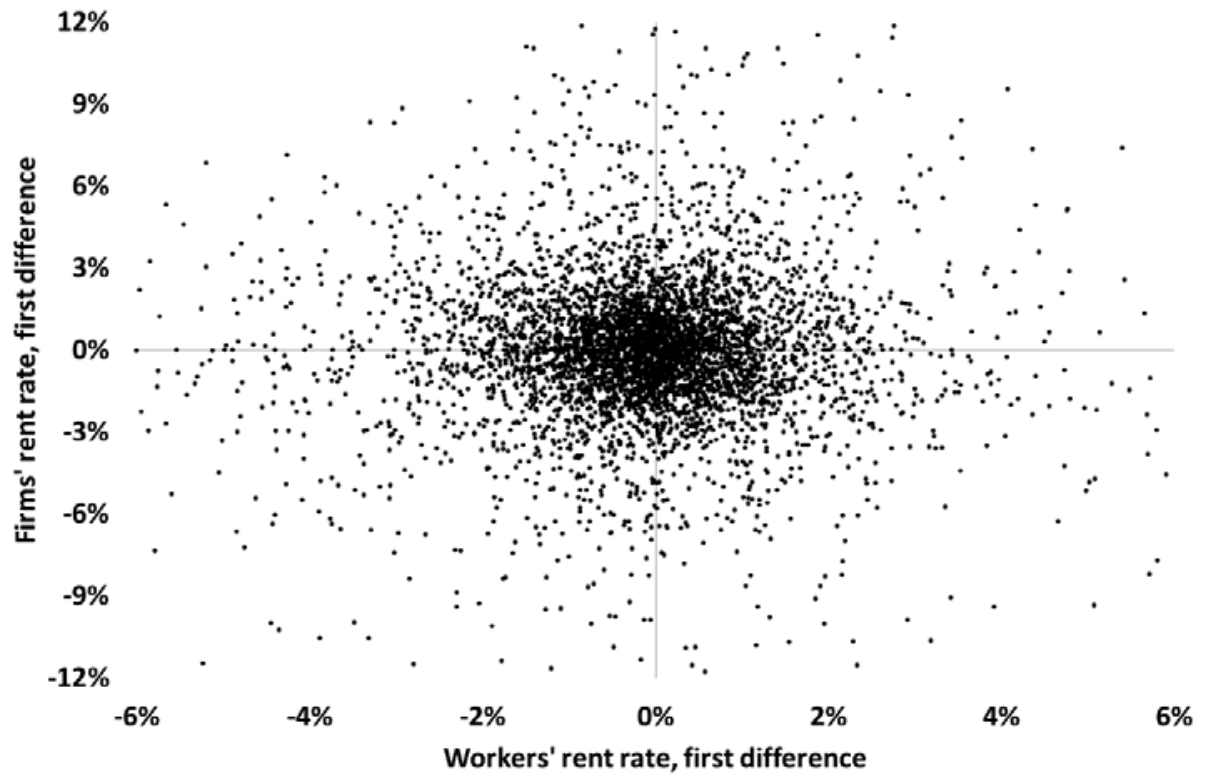

For convenience, the extreme values are excluded from this chart.

Chart 1 shows the observed density function of the mark-up rate $(M U R)$, its firm and worker components $\left(M U R^{f}\right.$ and $\left.M U R^{l}\right)$, and workers' share of rent (WSR). Our measure of the mark-up rate, which is relatively high on average $(36.8 \%)$, is shared equally between firms and workers (the average workers' share of rent is of $47.8 \%$ ). It leads to firms' and

8 Firms' rent rates are equal to 0 in five country*industry ( 95 observations), so workers' share of rent is equal to 1 , and the mark-up rate is equal to 1 or higher in eight country*industry (150 observations). For convenience, these observations are excluded from Chart 1. Our estimation results are strongly robust to the exclusion of these observations from the estimation samples. 
workers' rent rate distributions that are very close, with average rates of $20.4 \%$ and $16.4 \%$, respectively. However, this sharing differs a lot between country $\mathrm{x}$ industry $\mathrm{x}$ year, as shown by the spread of the density function (with a coefficient of variation of $38.0 \%$ ). This strong heterogeneity implies that our firms' rent rate, which is a standard measure of the mark-up rate assuming a perfect labor market, may be a noisy measure of the total mark-up rate and so of lack of competition.

Chart 2 also shows that changes in firms' and workers' rent rates are independent. Indeed, these rents move in the same direction as often as in opposite directions. This is as true for rent increases as for decreases (see Appendix A for more detailed information). It means that half of firms' rent increases (decreases) are achieved through the decreases (increases) in workers' rent and half through the sharing of total rent increases (decreases). Again, it means that firms' mark-up rate is not enough to understand total mark-up changes.

\section{LINKAGES BETWEEN OECD INDICATORS AND MEASURES OF MARK-UP AND RENT-SHARING}

There is an abundant literature using OECD anti-competitive Non-Manufacturing Regulation (NMR) indicators and Employment Protection Legislation (EPL) indicators as proxy for lack of competition in product market and of flexibility in labor market. In this section, we assess the linkages between these OECD regulation indicators and our measures of mark-up and workers' share of rents.

\subsection{Presentation of the OECD Regulation Indicators}

The OECD NMR and EPL indicators are based on detailed information on laws, rules and market settings. The values of these indicators are between 0 and 6 , with 0 for the most competitive/flexible regulations (for a descriptive analysis, see Appendix A). A main advantage of using such indicators in empirical analysis is that their construction can be held to be exogenous to productivity developments.

The OECD NMR indicators aim to measure to what extent competition and firm choices are restricted when there is no a priori reason for government interference, or when regulatory goals could plausibly be achieved by less coercive means. They cover energy (gas and electricity), transport (rail, road and air) and communication (post, fixed and cellular telecommunications), retail distribution and professional services, with country and time coverage varying across industries (see Conway and Nicoletti, 2007, for a more detailed presentation).

Our analysis treats separately a sub-domain of regulation: state control. The corresponding low-level OECD indicator, called NMR - State $\left(\mathrm{NMR}^{\mathrm{S}}\right)$ in this paper, takes into account the extent of public ownership in the network sectors, the control of strategic choices and price controls. We expect that the impact of state control on competition or bargaining power may be different than the other part of the OECD NMR indicators, called NMR Entry $\left(\mathrm{NMR}^{\mathrm{E}}\right)$, which takes into account barriers to entry, vertical integration and market structure.

The OECD EPL indicator aims to measure the procedures and costs involved in dismissing individual workers with regular contracts and workers on temporary contracts, including regulations on fixed-term and temporary work agency contracts (we do not use data on collective dismissal because these data are available only from 1998). It differs 
between countries and years, but not between industries (see OECD Employment Outlook 2013 for more information).

\subsection{LINKAGES WITH THE OECD INDICATORS: CHOICE OF SPECIFICATION}

According to Blanchard and Giavazzi's (2003) approach, product market regulations lead to rent creation, whereas labor market regulations affect rent-sharing. We investigate whether this is confirmed in the light of our new measures of mark-up and rent-sharing. We thus regress these two measures, $(M U R)$, and $(W S R)$, on the three OECD regulation indicators $\left(N M R^{E}\right),\left(N M R^{S}\right)$ and $(E P L)$. For further insight, we also regress the (WSR) components: workers' rent per hour $\left(\left(w-w^{r}\right) / P^{P I B}\right)$, number of hours worked per output unit $(N / Q)$ and rent per output unit $\left((P-C) / P^{P I B}\right)$ on the three OECD regulation indicators. For each of these five variables, say $y$ for simplicity, we estimate a regression equation specified as:

$$
\log \left(y_{c i t}\right)=\theta_{1} \times N M R_{c i t}^{E}+\theta_{2} \times N M R_{c i t}^{S}+\theta_{3} \times\left(\lambda_{i} \times E P L_{c t}\right)+\phi_{c i}+\phi_{c t}+u_{c i t}
$$

Where: $c, i, t$ are the country, industry and year indices; $N M R^{E}$ is the OECD NMR indicator excluding the state control component $N M R^{S} ;\left(\lambda_{i} \times E P L_{c t}\right)$ is the OECD indicator (EPL) interacted with $\lambda_{i}$ the intensity of the use of labor, measured by the industry labor share over production in the United States in 2000; $\theta_{k}, k=1,2,3$, are our parameters of interest; $\phi_{c i}$ and $\phi_{c t}$ are country* industry and country*year fixed effects; and $u$ the equation idiosyncratic error term.

The fixed effects $\phi_{c i}$ and $\phi_{c t}$ are included to control for various sources of endogeneity, such as omission bias and reverse causality which could stem in particular from governments implementing structural reforms. In order to identify the impact of the EPL indicator, which is not measured at the industry level, we assume that it depend on the intensity of the use of labor $\lambda$. We use to measure $\lambda$ the ratio of labor to output in the USA as this country exhibits the lowest EPL value in our sample, which we can consider as an appropriate benchmark. We shall call from now on $\left(\lambda_{i} \times E P L_{c t}\right)$ EPL - impact variable.

\subsection{LINKAGES WITH THE OECD INDICATORS: ESTIMATION RESULTS}

Tables 1 and 2 show the estimation results of relation (1), and sub-Sections 3.3.1 and 3.3.2 discuss these results, respectively. Section 3.3.1 presents the impact of OECD regulation indicators on our measures of the mark-up rate (MUR), workers' share of rent (WSR) and its components for all workers, whereas section 3.3.2 distinguishes between workers by skills levels. 


\subsubsection{MAIN ESTIMATES}

Table 1: Impact of regulation indicators on mark-up rate and rent-sharing

\begin{tabular}{|c|c|c|c|c|c|}
\hline & (1) & $(2)=(3)+(4)-(5)$ & (3) & (4) & (5) \\
\hline Dep. var. (log) & $\begin{array}{l}\text { Mark-up rate } \\
\qquad(\mu)\end{array}$ & $\begin{array}{c}\text { Workers' share } \\
\text { of rent }(\beta)\end{array}$ & $\begin{array}{c}\text { Workers' rent } \\
\text { per hour } \\
\left(\left(w-w^{r}\right) / P^{P I B}\right)\end{array}$ & $\begin{array}{c}\text { Hours worked } \\
\text { per output unit } \\
(N / Q)\end{array}$ & $\begin{array}{c}\text { Rent } \\
\text { per output unit } \\
\left((P-C) / P^{P I B}\right)\end{array}$ \\
\hline $\begin{array}{l}\text { NMR - Entry } \\
\left(N M R^{E}\right)\end{array}$ & $\begin{array}{c}0.0516 * * * \\
{[0.0107]}\end{array}$ & $\begin{array}{c}0.0644 * * * \\
{[0.0105]}\end{array}$ & $\begin{array}{c}0.0510^{* * *} \\
{[0.0111]}\end{array}$ & $\begin{array}{c}0.0744 * * * \\
{[0.0141]}\end{array}$ & $\begin{array}{c}0.0611 * * * \\
{[0.0116]}\end{array}$ \\
\hline NMR - State & $0.0229 * *$ & 0.00546 & -0.00696 & $0.0425^{* * *}$ & $0.0301 * *$ \\
\hline$\left(N M R^{S}\right)$ & {$[0.0112]$} & [0.0110] & {$[0.0100]$} & [0.0156] & {$[0.0120]$} \\
\hline EPL - impact & 0.0124 & -0.161 & $0.375^{* * *}$ & $-0.787 * * *$ & $-0.250 * * *$ \\
\hline$\left(\lambda_{i} \times E P L\right)$ & {$[0.0889]$} & [0.103] & {$[0.0950]$} & {$[0.0961]$} & {$[0.0913]$} \\
\hline Observations & 4,988 & 4,988 & 4,988 & 4,988 & 4,988 \\
\hline R-squared & 0.949 & 0.875 & 0.981 & 0.979 & 0.893 \\
\hline RMSE & 0.146 & 0.158 & 0.154 & 0.161 & 0.173 \\
\hline
\end{tabular}

Country*industry and country*year (separately for manufacturing and non-manufacturing industries) fixed effects.

Newey-West standard errors in brackets - *** $p<0.01,{ }^{* *} p<0.05, * p<0.1$

Note that the estimated coefficients in col. 2 are equal to the coefficients in col. 3 plus col. 4 minus col. 5 .

According to the estimation results in Table 1, NMR - Entry appears to have a positive and significant impact on the mark-up rate (column 1) and on workers' share of rent (column 2). This impact on workers' share of rent comes from a positive impact on both workers' rent per hour (column 3) and hours worked per output unit (column 4), which are higher than the impact on total rent per output unit (column 5). ${ }^{9}$ These results mean that an increase in barriers to entry, everything else being equal, reduces labor productivity and increases workers' rent per hour, which consequently increases workers' share of rent, and at the same time increases the mark-up rate.

NMR - State has a positive and significant impact on the mark-up rate (column 1), but a non-significant impact on workers' share of rent (column 2). This last result comes from the non-significant impact of NMR - State on workers' rent per hour (column 3), unlike NMR - Entry, while its positive and significant impacts on hours worked per output unit (column 4) and total rent per output unit (column 5) offset one another. These results mean that an increase in State control, everything else being equal, reduces labor productivity but has no significant impact on workers' rent per hour and consequently on workers' share of rent, and at the same time increases the mark-up rate.

These results concerning the impact of NMR (Entry and State) on the rent level and on the rent-sharing process seem to be consistent overall with the theoretical literature on the topic, and in particular with Blanchard and Giavazzi (2003) concerning the rent level. They confirm the interest of our mark-up rate measure as a measure of lack of competition.

The estimated coefficients of the impact of EPL - impact on the mark-up rate (column 1) and on workers' share of rent (column 2) are both non-significant. The non-significant impact on workers' share of rent comes from the negative impact on hours worked per output unit (column 4), which offsets the positive one on workers' rent per hour

\footnotetext{
9 Obviously, regulation effects on workers' rent per hour stem from effects on real wages per hour (see Appendix B for more details).
} 
(column 3) and the negative effect on total rent per output unit (column 5). These results mean that an increase in EPL, everything else being equal, has no impact on the mark-up rate, which is consistent with Blanchard and Giavazzi (2003). They also mean that this increase in EPL has no impact on workers' share of rent, which is at first sight more surprising. But this non-impact results from opposite effects. The positive impact on workers' rent per hour is consistent with the literature and suggests that an increase in EPL strengthens workers' wage bargaining power. But this direct wage impact and an indirect one, higher firing costs from the EPL increase, lead to a substitution between capital and labor and/or worker selection, which corresponds to a rise in labor productivity. This second channel is also consistent with the literature, for instance the negative impact of regulations on employment in Azmat et al. (2012).

We underline in Section II the issue raised by the capital user cost. Our measure of the lack of competition, the mark-up rate, assumes capital is fixed in the short run and so does not take into account the user cost of capital. However, this assumption is questionable and the omission of the capital user cost may affect our estimation results, particularly if regulations influence capital stocks. We therefore analyze the sensitivity of our relation (1) estimation results to the inclusion of capital intensity among the control variables and find that our estimation results are robust, despite the fact that NMR - State and EPL - Impact affect capital intensity (see Appendix D).

\subsubsection{ESTIMATES BY SKILLS}

Table 2: Impact of regulation indicators by skills level

\begin{tabular}{|c|c|c|c|c|c|c|}
\hline \multirow{3}{*}{$\begin{array}{l}\text { Dep. var. (log) } \\
\text { Skills } \\
\end{array}$} & (1) & (2) & (3) & (4) & (5) & $(6)$ \\
\hline & \multicolumn{3}{|c|}{ Workers' rent per hour } & \multicolumn{3}{|c|}{ Hours worked per output unit } \\
\hline & High & Medium & Low & High & Medium & Low \\
\hline $\begin{array}{l}\text { NMR - Entry } \\
\left(N M R^{E}\right)\end{array}$ & $\begin{array}{c}0.0467^{* * *} \\
{[0.0157]}\end{array}$ & $\begin{array}{c}0.0476 * * * \\
{[0.0154]}\end{array}$ & $\begin{array}{c}0.0416^{* *} \\
{[0.0167]}\end{array}$ & $\begin{array}{c}0.0778^{* * *} \\
{[0.0130]}\end{array}$ & $\begin{array}{c}0.0796 * * * \\
{[0.0146]}\end{array}$ & $\begin{array}{c}0.0884^{* * *} \\
{[0.0161]}\end{array}$ \\
\hline $\begin{array}{l}\text { NMR - State } \\
\left(N M R^{S}\right)\end{array}$ & $\begin{array}{l}-0.0301^{*} \\
{[0.0156]}\end{array}$ & $\begin{array}{l}-0.0197 \\
{[0.0142]}\end{array}$ & $\begin{array}{l}0.00710 \\
{[0.0148]}\end{array}$ & $\begin{array}{l}-0.0182 \\
{[0.0140]}\end{array}$ & $\begin{array}{c}0.0344^{* *} \\
{[0.0166]}\end{array}$ & $\begin{array}{l}0.0340^{*} \\
{[0.0183]}\end{array}$ \\
\hline $\begin{array}{l}\text { EPL - impact } \\
\left(\lambda_{i} \times E P L\right)\end{array}$ & $\begin{array}{c}0.100 \\
{[0.131]}\end{array}$ & $\begin{array}{c}0.545^{* * *} \\
{[0.112]}\end{array}$ & $\begin{array}{c}0.528^{* * *} \\
{[0.152]}\end{array}$ & $\begin{array}{c}-0.280 * * \\
{[0.134]}\end{array}$ & $\begin{array}{c}-0.824^{* * *} \\
{[0.109]}\end{array}$ & $\begin{array}{c}-1.293^{* * *} \\
{[0.122]}\end{array}$ \\
\hline Observations & 4,988 & 4,988 & 4,988 & 4,988 & 4,988 & 4,988 \\
\hline R-squared & 0.970 & 0.977 & 0.977 & 0.984 & 0.976 & 0.986 \\
\hline RMSE & 0.211 & 0.169 & 0.178 & 0.195 & 0.177 & 0.194 \\
\hline
\end{tabular}

Country*industry and country*year (separately for manufacturing and non-manufacturing industries) fixed effects.

Newey-West standard errors in brackets - *** $p<0.01, * * p<0.05, * p<0.1$.

Table 2 presents the estimation results of relation (1) for workers' rent per hour and hours worked per output unit at each of the three skills levels (high, medium and low).

The estimated coefficients of the impact of NMR - Entry on workers' rent per hour and on hours worked per output unit are both positive and significant, and do not differ within the three skills levels. The estimated coefficients of the impact of NMR - State on workers' rent per hour is slightly significant and negative only for the highly-skilled concerning workers' rent per hour (columns 1,2 and 3) and positive only for the medium- and low- 
skilled concerning hours worked per output unit (columns 4, 5 and 6). These results suggest that NMR - State slightly reduces wage inequality between highly-skilled workers and other workers, but also reduces highly-skilled employment relative to medium- and low-skilled employment.

The estimated coefficient of the impact of EPL - impact on workers' rent per hour is positive but significant only for the medium- and low-skilled, not for the highly-skilled (columns 1, 2 and 3). At the same time, the estimated coefficient of the impact of EPL impact on hours worked per output unit is negative and significant for the three levels of skills, but larger for the low-skilled than the highly-skilled (columns 4, 5 and 6). These results suggest that an increase in EPL - impact raises the wages of low- and mediumskilled workers, but not of highly-skilled ones, who are the least protected by EPL. This direct cost impact and the indirect one mentioned above (an increase in EPL means higher firing costs that firms can consider as an increase in the cost of labor) lead to a substitution mechanism between production factors detrimental to labor. The fact that, in the case of highly-skilled workers, there is a significant impact on hours worked per output unit (column 4), even with no significant impact on workers' rent per hour (column 1) could correspond to the indirect labor cost effect of a change in EPL. These results are consistent with those of Cette, Lopez and Mairesse (2016b). Taken together, the estimation results in Table 2 and Table 1 column (5) indicate that EPL greatly reduces workers' share of rent for low-skilled workers, whereas it has a tiny impact on this share for medium- and highlyskilled workers.

\section{IMPACT OF THE MARK-UP RATE AND EXTENT OF RENT- SHARING ON TFP}

The previous section confirms the relationship of our measures of the mark-up rate and workers' bargaining power with lack of competition and workers' bargaining power. We now investigate their effects on TFP.

\subsection{Presentation OF THE TFP Measure and ESTIMATED SPECIFICATION}

To measure productivity, we build a total factor productivity (TFP) index. We first compute capital stocks using the permanent inventory method with a $10 \%$ depreciation rate and EU-KLEMS investment data. ${ }^{10}$ Second, TFP growth rates are calculated using the OECD STAN database as follows (indices omitted):

$$
\Delta \log T F P=\Delta \log \frac{V A}{N}-(1-s) \times \Delta \log \frac{K}{N}
$$

Where $V A$ is value added at constant prices, $N$ the total number of hours worked, $K$ the capital stock at constant prices and $s$ the output elasticity of labor, approximated by the industry-specific average of US labor share on value added. Finally, the TFP level is calculated for a base year using OECD national purchasing power parity indexes and then extended over the sample period using our measure of TFP growth.

10 For sensitivity analysis, we also compute other TFP measures taking into account capital stock composition: information and communication technology (ICT) equipment, non-ICT equipment, construction and R\&D capital. The estimation results are strongly robust to the choice of TFP measure. 
We estimate the impact of the lack of competition and workers' bargaining power on this TFP measure according to the following equation:

$$
\begin{aligned}
\log \left(T F P_{c i t}\right)= & \rho \times \log \left(T F P_{i t-1}^{U S}\right)+\alpha \times \log \left(M U R_{c i t-1}\right)+\gamma \times \log \left(W S R_{c i t-1}\right)+\xi_{c i} \\
& +\xi_{c t}+\epsilon_{c i t}
\end{aligned}
$$

Where: TFP and TFP ${ }^{\mathrm{US}}$ are domestic and US total factor productivity; $\rho, \alpha$ and $\gamma$ our parameters of interest; $\xi_{c i}$ and $\xi_{c t}$ fixed effects; and $\epsilon$ the estimation residuals. The inclusion of US TFP takes into account catch-up effects as well as various industry-specific common correlated unobserved factors, such as technological change.

\subsection{ESTIMATION RESULTS}

Table 3: Impact of mark-up rate and rent-sharing on TFP

Dependent variable: TFP, in logarithm $(\log (T F P))$

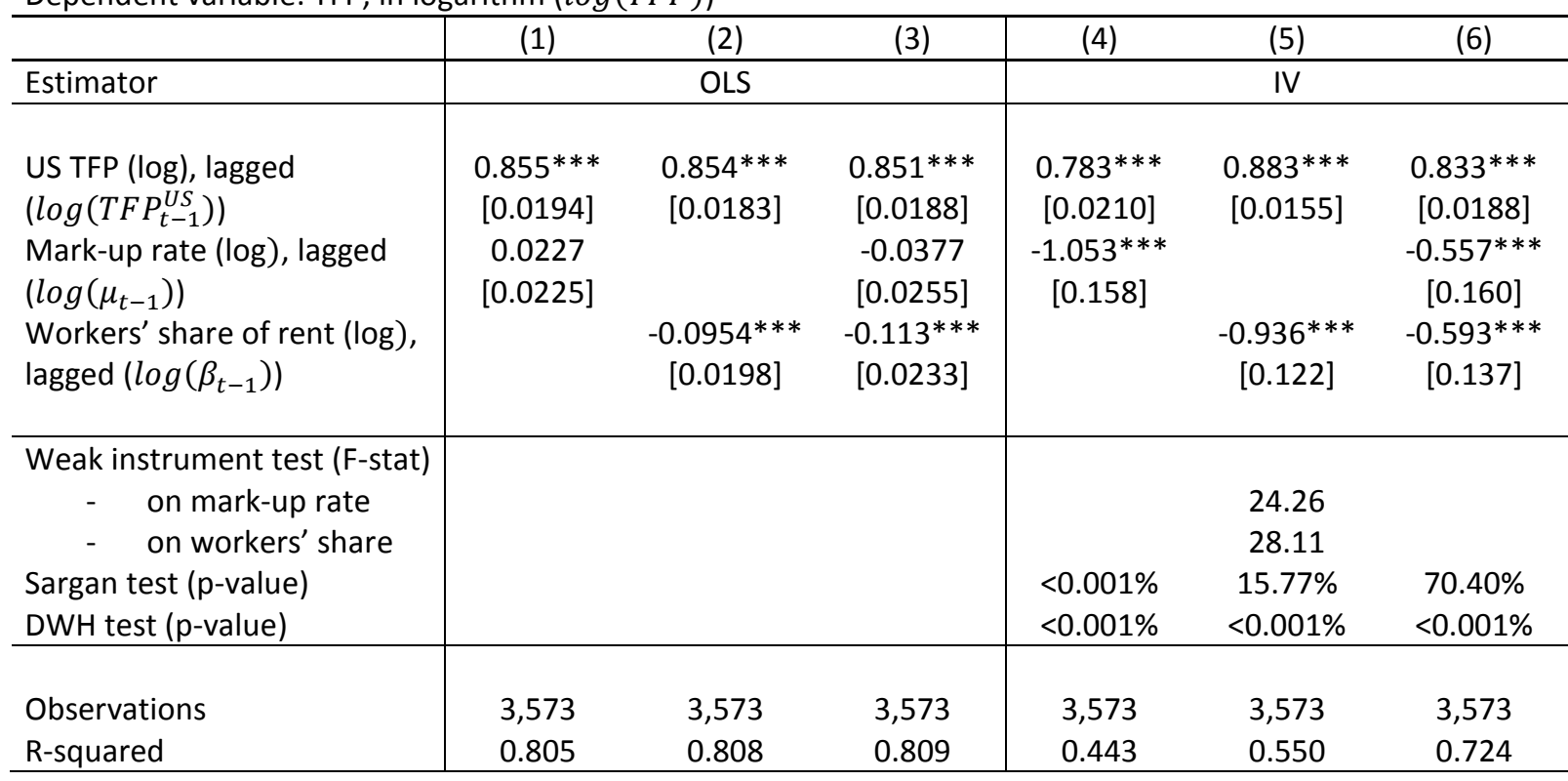

Country*industry and country*year (separately for manufacturing and non-manufacturing industries)

fixed effects.

Newey-West standard errors in brackets - *** $p<0.01, * * p<0.05, * p<0.1$.

Leads and lags of US TFP and capital intensity (log) first differences included.

Instruments: NMR-Entry and NMR-State and NMR - Entry $\times$ NMR - State.

Table 3 shows the estimation results for relation (2). These estimates are first carried out using the OLS method (columns 1,2 and 3). But considering the possible endogeneity issues between explained and explanatory variables (for example, a demand shock can temporarily impact both the TFP and the mark-up rate), we also perform IV regressions (columns 4, 5 and 6), the two explanatory variables mark-up rate and workers' share of rent being instrumented. The pool of instruments are the two product market regulation indicators (NMR - Entry) and (NMR - State) and their product (NMR - Entry) x (NMR - 
State). ${ }^{11}$ From a theoretical point of view, considering the content of the regulation indicators, which are built from detailed information on laws, rules and market and industry settings, these instruments can arguably be thought of as exogenous with respect to explained variables. First-stage regressions indicate that all the instruments are highly significant. The Sargan tests confirm our assumption of the instruments' exogeneity (column 5 and 6), except when workers' share of rent is omitted (column 4), which may be explained by the low power of this test on our data. The Durbin-Wu-Hausman (DWH) test confirms the endogeneity of the mark-up rate and workers' share of rent. ${ }^{12}$

The estimated coefficient corresponding to the process of catching up to the US TFP level is high and stable over the different estimates, which is a usual result. The estimated coefficient of the mark-up rate is negative and significant, as expected, but only for IV estimates (columns 4 and 6). This suggests that less competition, here measured through a higher mark-up rate, reduces the incentive to innovate, with lower TFP as a result. The estimated coefficient of workers' share of rent is negative and significant, as expected, both on OLS (columns 2 and 3) and IV (columns 5 and 6) estimates, the estimated value being larger with IV estimates. This result suggests that, everything else being equal (and in particular for a given level of rents), an increase in workers' share of rent reduces the firm's incentive to innovate but also its own resources to finance innovation, with lower TFP as a result. These results confirm that lack of competition on the product market and labor market has a detrimental impact on TFP. They are also consistent with the literature (see, for example, and also for a literature review Cette, Lopez and Mairesse, 2016a).

\subsection{POLICY SIMULATION}

To illustrate the meaning of our estimation results, we compute from them and for all countries in our dataset the TFP gains from changes to competition. In order to take into account of changes in the mark-up rate resulting only from these competition changes, we follow the same approach as for the estimations: we compute first the impacts of NMR reforms on the mark-up rate and workers' bargaining power, and then the effects of both on TFP. The illustrating NMR reform corresponds to the adoption of the lowest NMR Entry and NMR - State 2013 levels, 2013 being the last year the NMR indicators were available. The adoption of these lowest levels of regulation would require very large-scale product market structural reforms in some countries, such as France and Italy. The implementation of such reforms cannot be considered politically or socially realistic in the short to medium term.

The impact of structural reforms is calculated at the industry level using the main estimates (given in Table 1, column 1 and 2, and Table 3, column 6) for our five non-manufacturing industries, then these effects are aggregated at the national level using the value added industry shares in the whole economy for each country (these five non-manufacturing industries account for one third of country value added on average). The country level impact depends, for each variable, on the NMR - Entry and NMR - State differentials with the lowest levels. It corresponds to a long-term impact, after dynamic adjustments not evaluated here. Chart 2 presents the results of this simulation (see Appendix E for the

\footnotetext{
${ }^{11}$ The OECD NMR indicators are available for five industries: energy, transport, communication, retail distribution and professional services. Therefore, the IV estimates of the impact of the mark-up rate and workers' share of rent only mobilized the data variability of these five industries. The estimation results are robust when the estimation sample is reduced to these five industries.

${ }^{12}$ US TFP may also be endogenous, in particular with respect to an omission bias. We have explored this issue by implementing the Dynamic OLS approach, introducing leads and lags of first difference US TFP into our estimated regressions. Our estimation results are robust, as shown in Appendix C.
} 
contributions to the TFP gains of each regulated industry). The two main points to bring out from them are the following:

The overall impact is the largest (more than 5\% TFP gains at the country level) in Italy and France, followed Austria, Spain and Canada (more than 4\%). These countries suffer from the highest levels of anti-competitive regulation. At the other end of the scale, it is the smallest in Sweden, Australia and the United Kingdom (less than 2\%), followed by the Netherlands (less than 3\%), which appear to be the least regulated countries. These figures confirm that the gains that could be expected from the implementation of ambitious product market reforms could be large in many countries (gains of $3.6 \%$ on average).

In all countries, the TFP gains come mainly from the adoption of the lowest levels of NMR - Entry. The gains from the adoption of the lowest levels of NMR - State appear to be much smaller in all countries. This result suggests that the priority in reforming the product market is more to reduce barriers to entry than to decrease State control.

\section{CONCLUSION}

We have proposed new measures of mark-up and workers' share of rents, inspired by Dobbelaere and Mairesse (2015) approach regarding firm-level data. Our empirical investigation is based on a cross-country-industry panel covering 14 OECD countries and 19 industries over the 1985-2005 period. We find that: (i) our new measure of the mark-up rate provides a different view of competition than a mark-up rate assuming perfect labor markets; (ii) the NMR indicator influences positively the mark-up rate and workers' bargaining power; (iii) the EPL indicator has no significant impact on the mark-up rate but a positive impact on workers' rent per hour; iv) EPL impacts hours worked per output unit negatively, which offsets the increase in workers' rent per hour and leads to a nonsignificant impact of EPL on workers' bargaining power; (v) lack of competition on the product market and of flexibility on the labor market (measured through our original indicators) have a detrimental impact on TFP.

Our simulations show that a decrease in mark-up rates and workers' bargaining power that would result from a switch of countries' NMR to the lowest NMR levels in 2013 might lead to an average increase in TFP of 3.7\% in the long run. But the adoption of these levels of lowest regulation would require very large-scale product market structural reforms in some countries, such as France and Italy. The implementation of such reforms cannot be considered politically or socially realistic in the short to medium term.

The original findings of this paper give more content to the channels of the impact of market (both product and labor) regulation on the rent-building and rent-sharing processes. They also confirm that the impact of regulations on productivity occurs via lack of competition and labor market flexibility. A limitation of our investigation concerns the distinction between short- and long-run effects. Our estimation results using static specifications may be interpreted as long-run estimates, but short-run changes are important in understanding the mechanisms for and political feasibility of reforms. The use of a dynamic approach, such as an Error Correction Model, would be interesting but hard to implement because of the lack of time variability in our regulation indicators, particularly the EPL indicator. We are probably at the limit of the use of a cross-country-industry panel dataset, and some corroboration may be needed, perhaps from firm-level data. 


\section{REFERENCES}

Askenazy, Philippe, Gilbert Cette and Paul Maarek (2018): “Rent-sharing and workers' bargaining power: an empirical cross-country/cross-industry panel analysis", The Scandinavian Journal of Economics, forthcoming.

Azmat, Ghazala, Alan Manning and John Van Reenen (2012): "Privatization and the Decline of Labour's Share: International Evidence from Network Industries", Economica, 79(315), July, pp. 470-492.

Barone, Guglielmo and Federico Cingano (2011): "Service regulation and growth: evidence from OECD countries”, The Economic Journal, 121(555), pp. 931-957.

Bassanini, Andrea, Luca Nunziata and Danielle Venn (2009): "Job protection legislation and productivity growth in OECD countries", Economic Policy, 24(04), pp. 349-402.

Blanchard, Olivier and Francesco Giavazzi (2003): "Macroeconomic Effects of Regulation and Deregulation in Goods and Labor Markets", The Quarterly Journal of Economics, 118(3), pp. 879-907.

Cette, Gilbert, Jimmy Lopez and Jacques Mairesse (2016a): "Market Regulations, Prices, and Productivity", American Economic Review, American Economic Association, 106(5), pp. 104-108.

Cette, Gilbert, Jimmy Lopez and Jacques Mairesse (2016b): "Labor market regulations and capital intensity”, NBER Working Papers, 22603, September.

Conway, Paul, Donato de Rosa, Giuseppe Nicoletti and Faye Steiner (2006): "Product Market Regulation and Productivity Convergence", OECD Economic Studies, 43, pp. 3976.

Conway, Paul and Giuseppe Nicoletti (2007): "Product Market Regulation and Productivity Convergence: OECD Evidence and Implications for Canada", International Productivity Monitor, 15, pp. 3-24.

Dobbelaere, Sabien and Jacques Mairesse (2013): "Panel Data Estimates of the Production Function and Product and Labor Market Imperfections", Journal of Applied Econometrics, 28(1), pp. 1-46.

Dobbelaere, Sabien and Jacques Mairesse (2015): "Comparing micro-evidence on rent sharing from three different approaches", MERIT Working Papers 029, United Nations University - Maastricht Economic and Social Research Institute on Innovation and Technology (MERIT).

Dobbelaere, Sabien and Jacques Mairesse (2018): "Comparing micro-evidence on rent sharing from two different econometric models", forthcoming in Labor Economics.

Griffith, Rachel, Rupert Harrison and Helen Simpson (2010): "Product Market Reform and Innovation in the EU", Scandinavian Journal of Economics, 112(2), pp.389-415

Jean, Sébastien and Giuseppe Nicoletti (2015): "Product market regulation and wage premia in Europe and North America: An empirical investigation", International Economics, 144, pp. 1-28.

Nicoletti, Giuseppe, and Frederic Pryor (2006): "Subjective and objective measures of governmental Regulations", Journal of Economic Behavior \& Organization, 59, pp. 433449.

Spector, David (2004): "Competition and the capital-labor conflict", European Economic Review, 48, pp. 25-38. 


\section{APPENDIX A: DESCRIPTIVE ANALYSIS}

This appendix completes the descriptive analysis in Section II of our measures of the markup rate and rent-sharing, and then presents the values of the OECD regulation indicators and the country sample average of the TFP gap with the United States.

Table A1 shows the distribution of the mark-up rate, workers' share of rent and its components, in level (Table A1A) and difference form (Table A1.B). The numerical values in columns (1) to (4) of Table A1. A columns correspond to Chart 1. The values of hours worked per output unit and rent per output unit in level, given in columns (6) and (7) of Table A1.A, cannot be interpreted directly as the difference between industries depends on the output deflator level, so we introduce the rent per hour variable, in column (8), which is the ratio of rent per output unit to hours worked per output unit and is independent of the deflator. The median value of this rent per hour is 19 \$ (in 2000 US PPP) and workers' rent per hour, column (5), 8 \$, with large heterogeneity for both, but much greater for total rent. Table A1.B columns (2) and (3) shows the distributions of workers' and firms' mark-up rate first differences used in Chart 2, and Table A2 shows the relationship between these first differences. The median and mean changes are small for each variable, with sometimes high increases being offset by equivalent decreases.

Chart A1 completes this view of our measures of the mark-up rate and rent-sharing, introducing firms' and workers' rent rate $\left(\mu^{f}\right.$ and $\left.\mu^{l}\right)$ by industry (Chart A1.A), or country (Chart A1.B) or year (Chart A1.C). Chart A1 makes it possible to observe both the markup rate - the sum of firms' and workers' rent rate - and the rent-sharing. The mark-up rate varies greatly between industries, with lower values for manufacturing industries. Among non-manufacturing industries, the mark-up rate is very high for three industries, 'electricity, gas and water supply', 'communications' and 'financial intermediation', and very low for 'hotels and restaurants'. Workers' share of rent is particularly low in two of the high markup rate industries, the 'electricity, gas and water supply' and 'communications'. Focusing on countries, we observe that Canada and the United States have the highest mark-up rates. It may be explained by other factors than lack of competition, for instance innovation, education and risk-taking, showing the need to use the Instrumental Variable estimation method in Section IV in order to mobilize only the mark-up variability explained by competition changes when estimating the impact of competition on TFP. The lowest workers' share of rent is in the Czech Republic. Finally, we observe relatively stable markup rates and rent-sharing over time.

Charts A2 to A4 show the values of the OECD regulation indicator and Chart A5 the country sample average TFP gap with the US (i.e. the ratio of domestic TFP to US TFP), for each sample country and the years 1985 (or the first year available for TFP) and 2005. We observe a decrease in the regulation indicators over time, with a very strong fall in NMR - Entry, a smaller but significant reduction in NMR - State and weaker changes concerning EPL, with even small increases in some countries. We can also observe that large differences between countries remain in 2005. We do not observe a catch-up effect in Chart A5 but, as mentioned in Section III, the inclusion of US TFP in our estimated specification is also motivated by various industry-specific common correlated unobserved factors, such as technological change. 
Table A1: Univariate descriptive analysis

$\underline{\text { A - Level values }}$

\begin{tabular}{|c|c|c|c|c|c|c|c|c|}
\hline 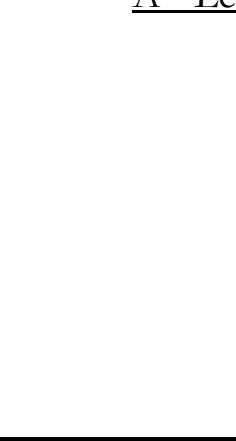 & $\begin{array}{l}(1)=(2)+ \\
(3)\end{array}$ & $\begin{array}{l}\text { Firms' } \\
\text { rent } \\
\text { rate } \\
\left(\mu^{f}\right)\end{array}$ & $\begin{array}{l}\text { Worker } \\
\mathrm{s}^{\prime} \text { rent } \\
\text { rate } \\
\left(\mu^{l}\right)\end{array}$ & $\begin{array}{l}(4)=(5) \mathrm{x}(6) / \\
(7) \\
\text { Workers' } \\
\text { share of } \\
\text { rent }(\beta)\end{array}$ & $\begin{array}{l}(5) \\
\text { Workers' } \\
\text { rent } \\
\text { per } \\
\text { hour* } \\
\left(\frac{w-w^{r}}{P^{P I B}}\right)\end{array}$ & $\begin{array}{l}(6) \\
\text { Hours } \\
\text { worked } \\
\text { per } \\
\text { output } \\
\text { unit** } \\
(N / Q)\end{array}$ & $\begin{array}{l}(7) \\
\text { Rent } \\
\text { per } \\
\text { output } \\
\text { unit* } \\
\left(\frac{P-C}{P^{P I B}}\right)\end{array}$ & $\begin{array}{l}(8)= \\
(7) /(6) \\
\text { Rent per } \\
\text { hour* } \\
\left(\frac{P-C}{P^{P I B}} \frac{Q}{N}\right)\end{array}$ \\
\hline Mean & $36.79 \%$ & $20.37 \%$ & $16.41 \%$ & $47.77 \%$ & 8.92 & 17.01 & 0.25 & 45.94 \\
\hline $\begin{array}{l}\text { Standard- } \\
\text { error }\end{array}$ & $25.42 \%$ & $18.82 \%$ & $11.16 \%$ & $18.16 \%$ & 5.47 & 14.87 & 0.18 & 89.21 \\
\hline Min & $3.78 \%$ & $0.00 \%$ & $2.35 \%$ & $5.76 \%$ & 0.53 & 0.03 & 0.00 & 1.09 \\
\hline p1 & $6.59 \%$ & $0.00 \%$ & $3.20 \%$ & $12.84 \%$ & 0.88 & 0.07 & 0.01 & 2.08 \\
\hline p5 & $12.99 \%$ & $4.12 \%$ & $4.53 \%$ & $20.66 \%$ & 1.56 & 0.12 & 0.02 & 4.70 \\
\hline p10 & $15.28 \%$ & $6.61 \%$ & $5.69 \%$ & $26.02 \%$ & 2.63 & 0.21 & 0.02 & 6.34 \\
\hline p25 & $21.08 \%$ & $9.78 \%$ & $9.20 \%$ & $35.46 \%$ & 4.93 & 6.98 & 0.14 & 11.58 \\
\hline p50 & $29.62 \%$ & $14.55 \%$ & $13.58 \%$ & $45.78 \%$ & 8.09 & 14.13 & 0.23 & 19.08 \\
\hline p75 & $41.77 \%$ & $23.14 \%$ & $20.43 \%$ & $57.77 \%$ & 11.94 & 24.02 & 0.33 & 38.78 \\
\hline p90 & $71.53 \%$ & $42.90 \%$ & $29.91 \%$ & $72.06 \%$ & 16.55 & 35.53 & 0.47 & 105.01 \\
\hline p95 & $90.66 \%$ & $58.39 \%$ & $39.90 \%$ & $82.07 \%$ & 19.31 & 45.32 & 0.58 & 166.68 \\
\hline p99 & $137.45 \%$ & $\begin{array}{l}105.35 \\
\%\end{array}$ & $53.86 \%$ & $100.00 \%$ & 25.47 & 68.86 & 0.82 & 461.44 \\
\hline Max & $196.88 \%$ & $\begin{array}{l}134.95 \\
\%\end{array}$ & $\begin{array}{l}114.47 \\
\%\end{array}$ & $100.00 \%$ & 32.99 & 106.65 & 1.45 & 1045.88 \\
\hline Observations & 4,988 & 4,988 & 4,988 & 4,988 & 4,988 & 4,988 & 4,988 & 4,988 \\
\hline
\end{tabular}




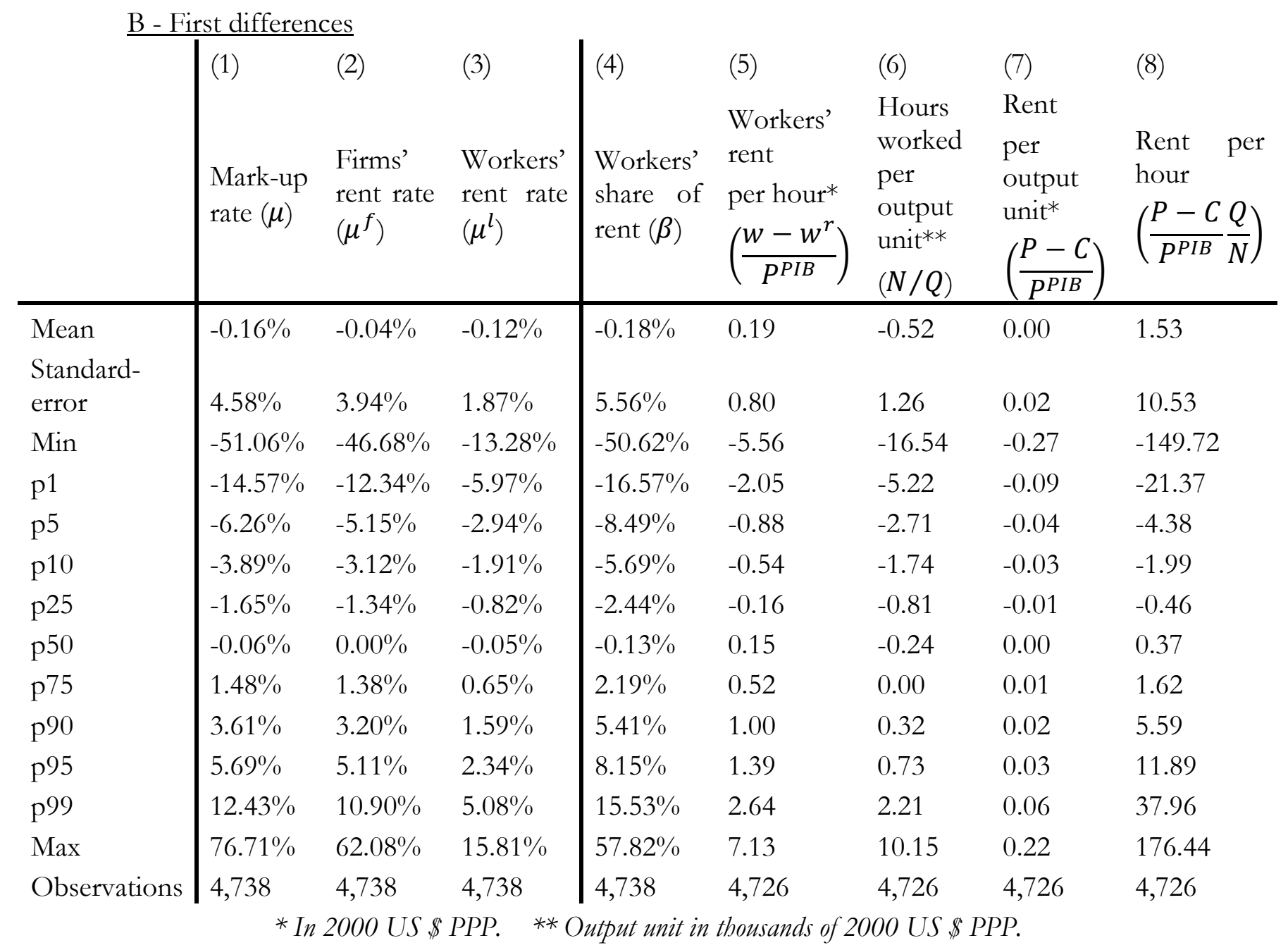

Table A2: Occurrence of positive/negative changes in firms' and workers' rent rates

$\begin{array}{llll} & \Delta \mu^{l} \leq 0 & \Delta \mu^{l}>0 & \text { Total } \\ \Delta \mu^{f} \leq 0 & 1,252 & 1,154 & 2,406 \\ \Delta \mu^{f}>0 & 1,222 & 1,110 & 2,332 \\ \text { Total } & 2,474 & 2,264 & 4,738\end{array}$




\section{Chart A1: Firms' and workers' rent rate by country, industry and year}

\section{$\underline{A-B y}$ industry}

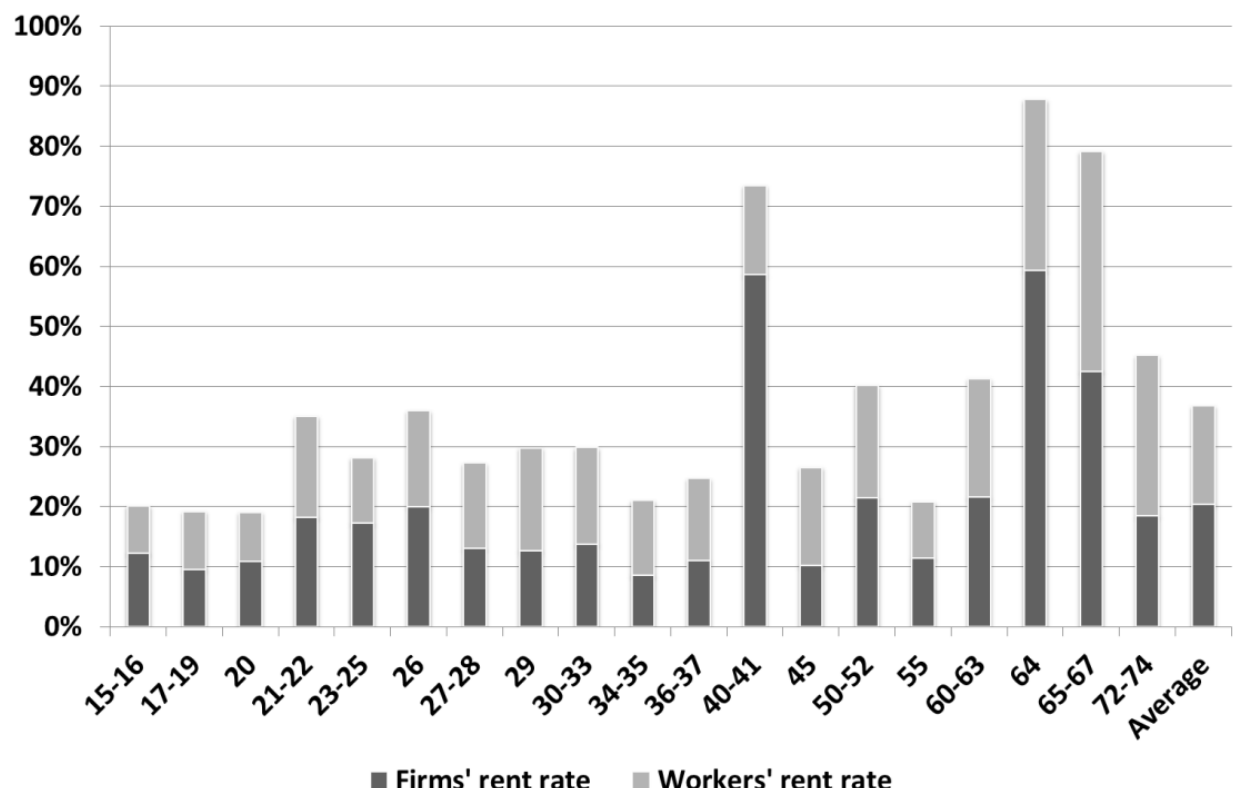

ISIC rev. 3 codes are presented for each of the following industries (ISIC code in brackets): food products (15-16), textiles (17-19), wood products (20), paper (21-22), chemicals products (23-25), non-metallic mineral products (26), metal products (27-28), machinery n.e.c. (29), electrical equipment (30-33), transport equipment (34-35), manufacturing n.e.c. (36-37), electricity, gas and water supply (40-41), construction (45), retail (50-52), hotels and restaurants (55), transport and storage (60-63), communications (64), financial intermediation (65-67), renting of equipment and other business activities (72-74).

\section{$\underline{B}-$ By country}

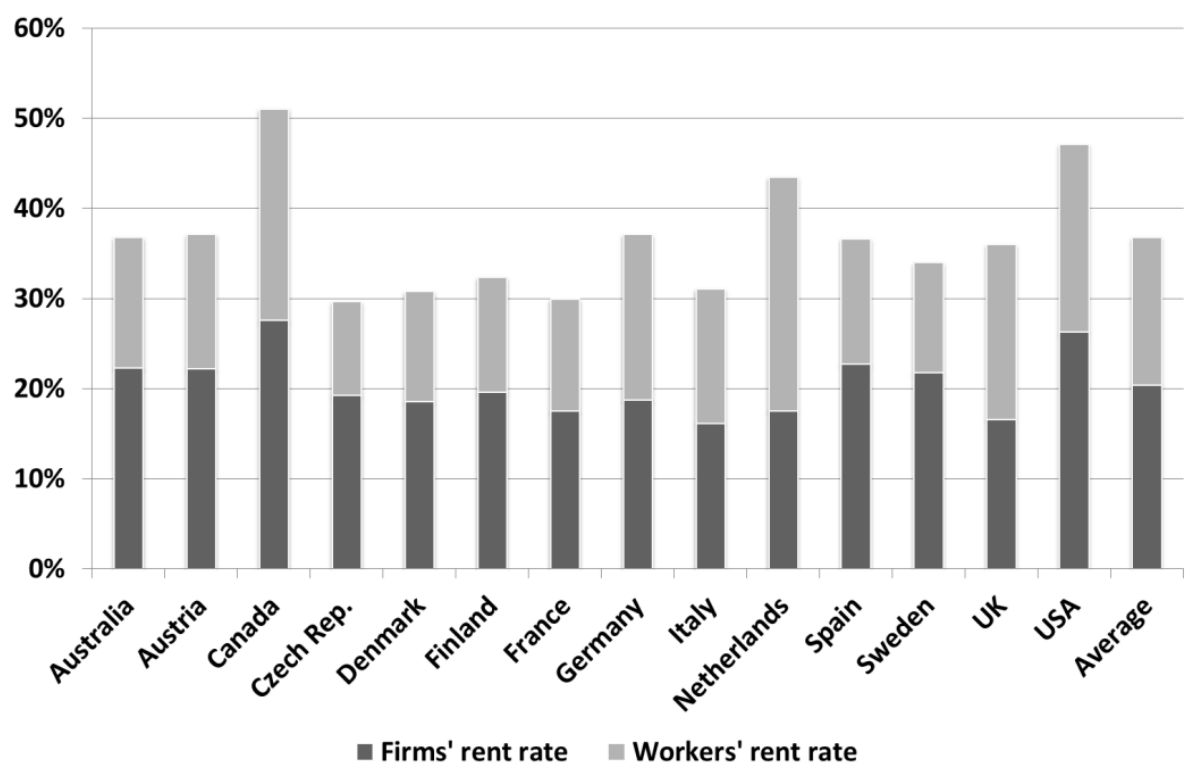




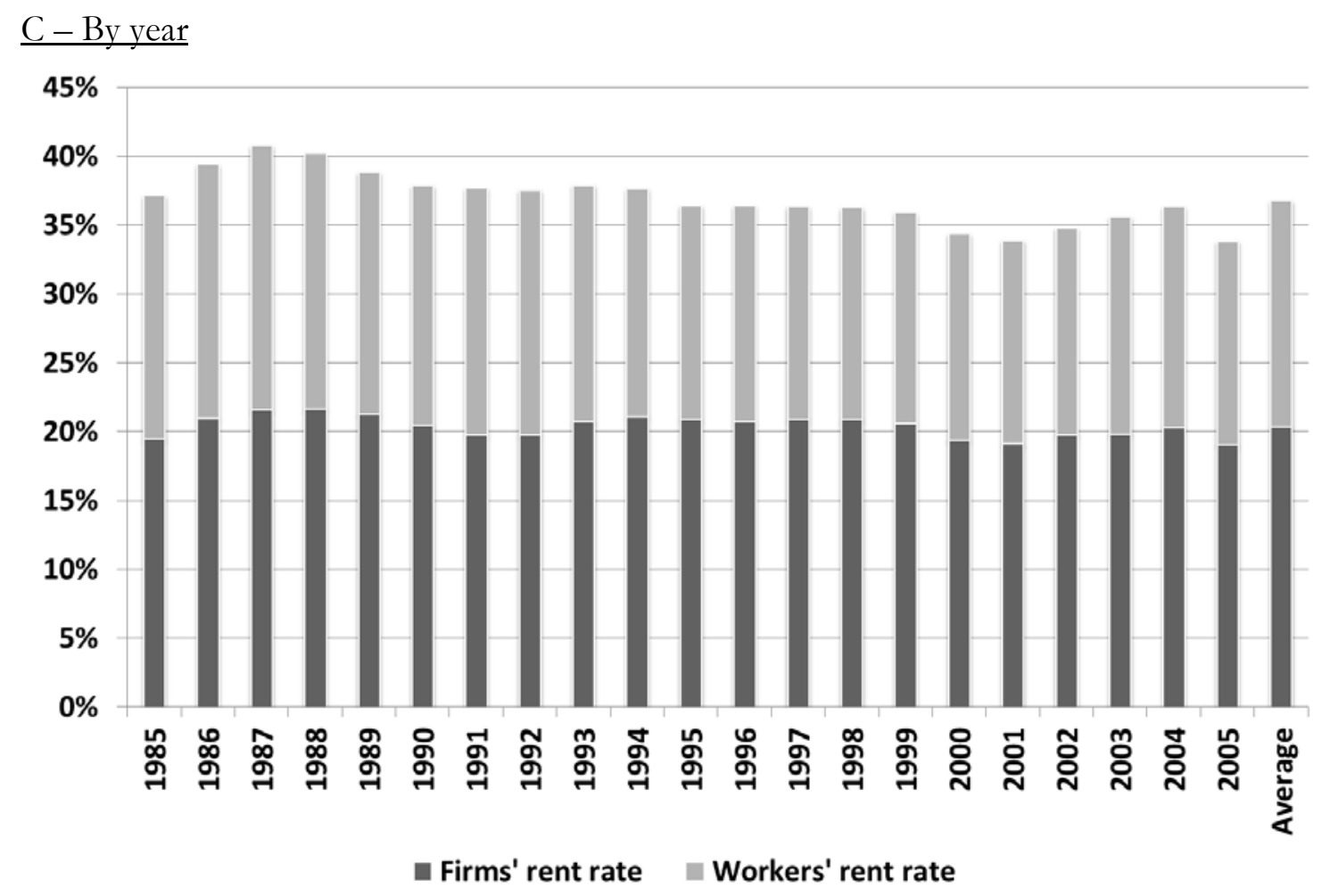

Chart A2: OECD NMR - Entry indicator

Scale: $0-6$, with 0 for the most pro-competitive regulations

30

25

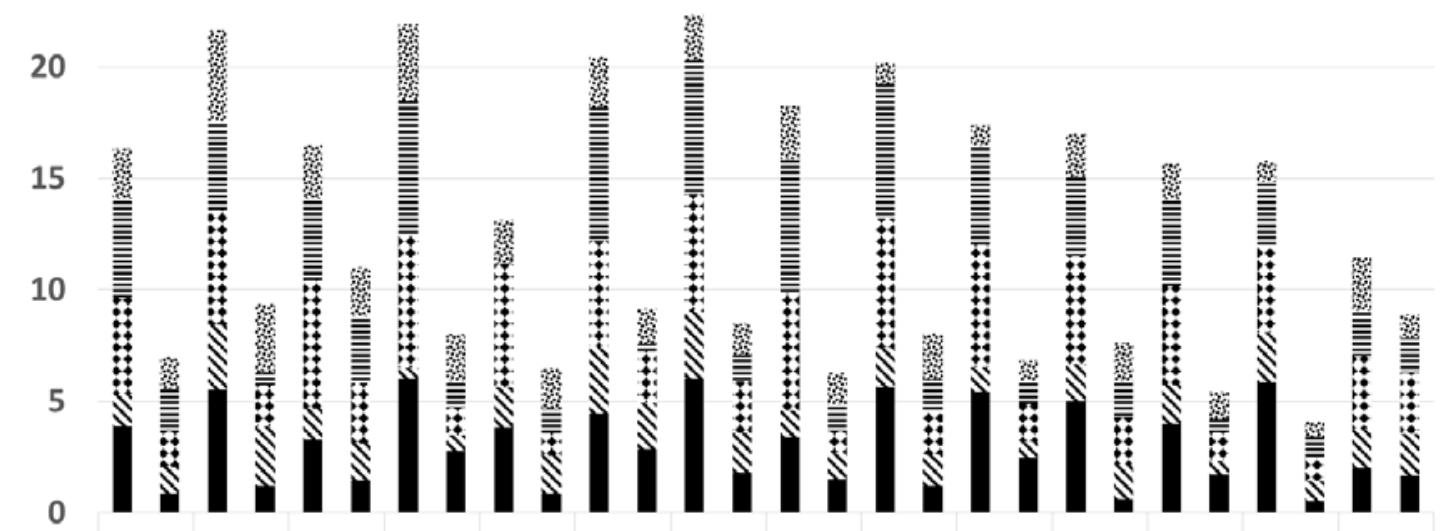

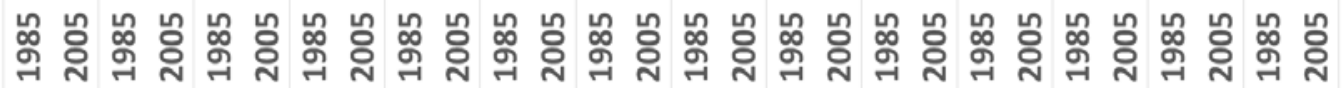

AUS AUT CAN CZE DNK FIN FRA GER ITA NLD SPN SWE UK US

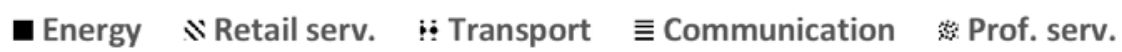




\section{Chart A3: OECD NMR - State indicator}

Scale: 0-6, with 0 for the most pro-competitive regulations

30

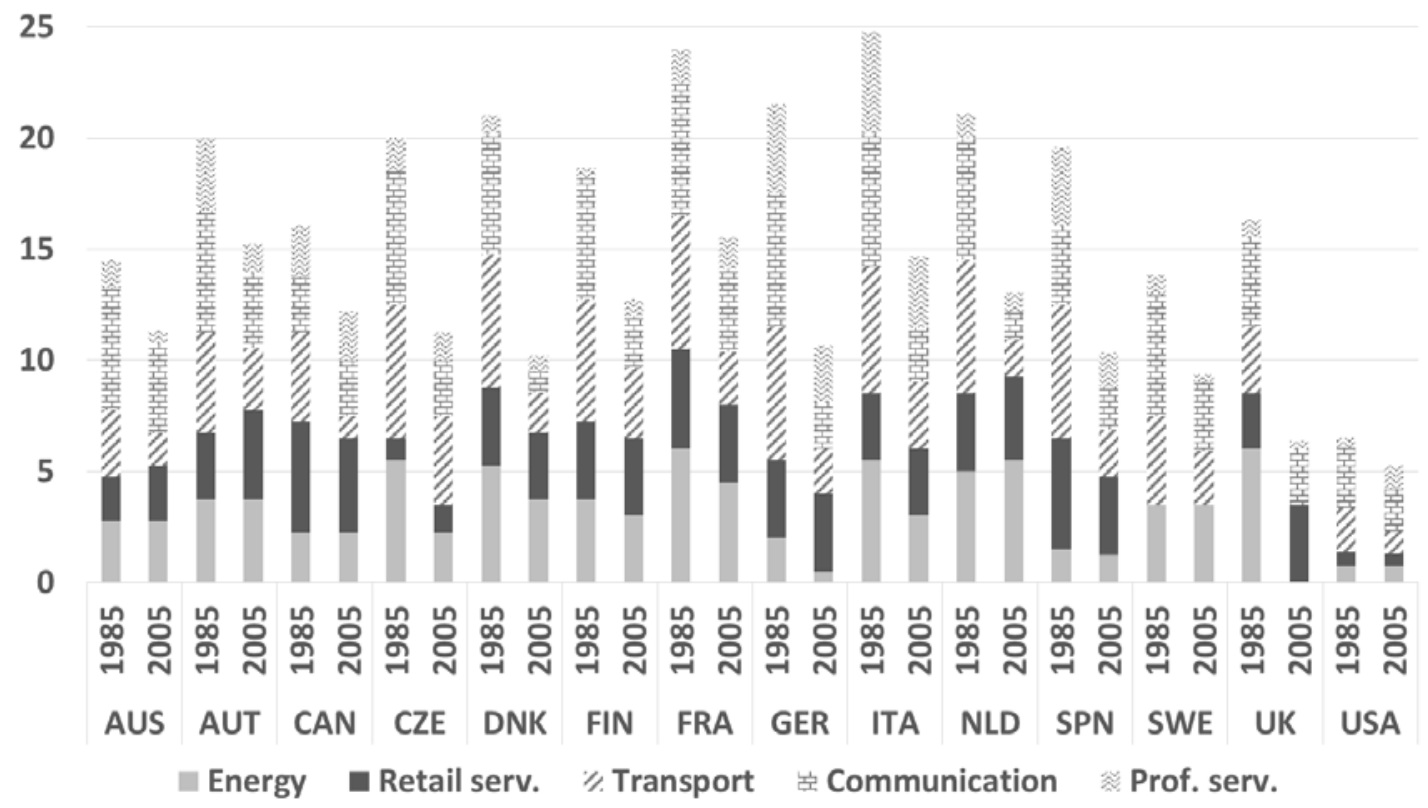

\section{Chart A4: OECD Employment Protection Legislation indicator}

Scale: $0-6$, with 0 for the most flexible regulations

6

5

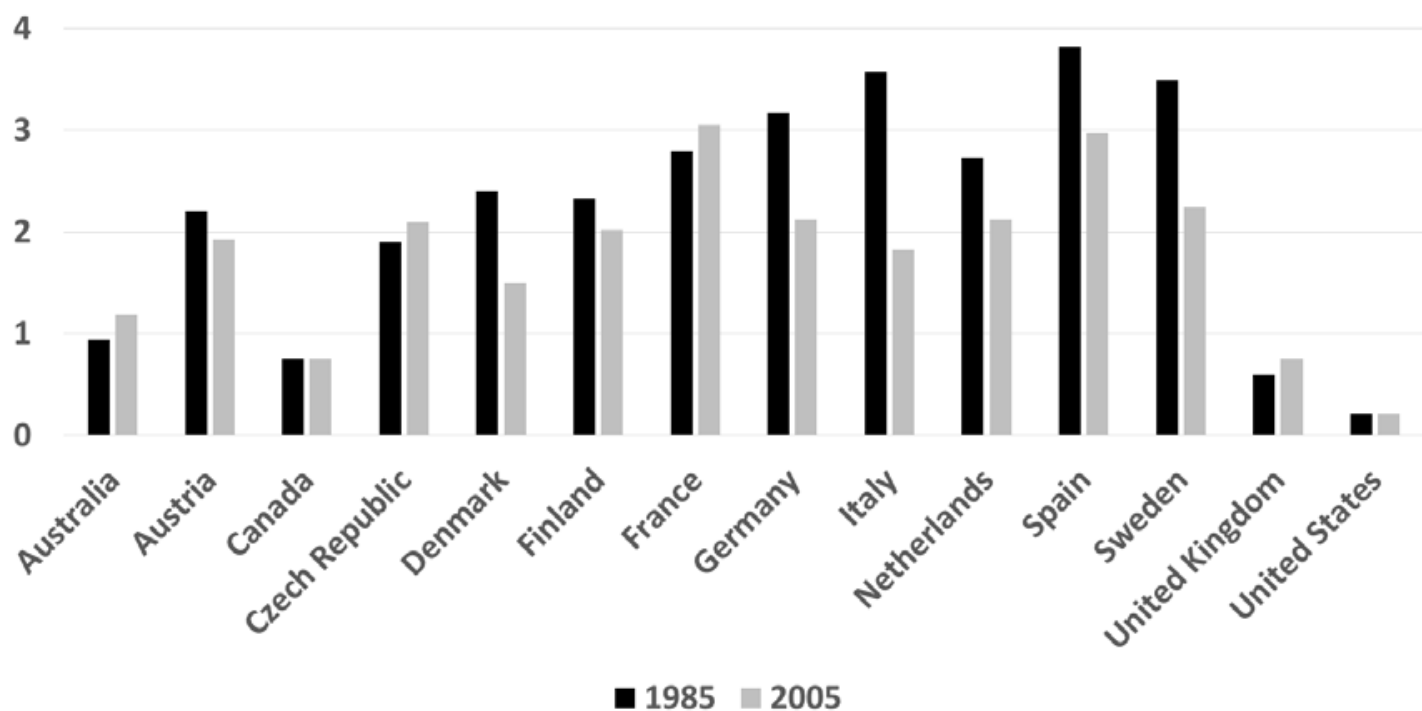


Chart A5: Country sample average TFP relative to US TFP

1.2

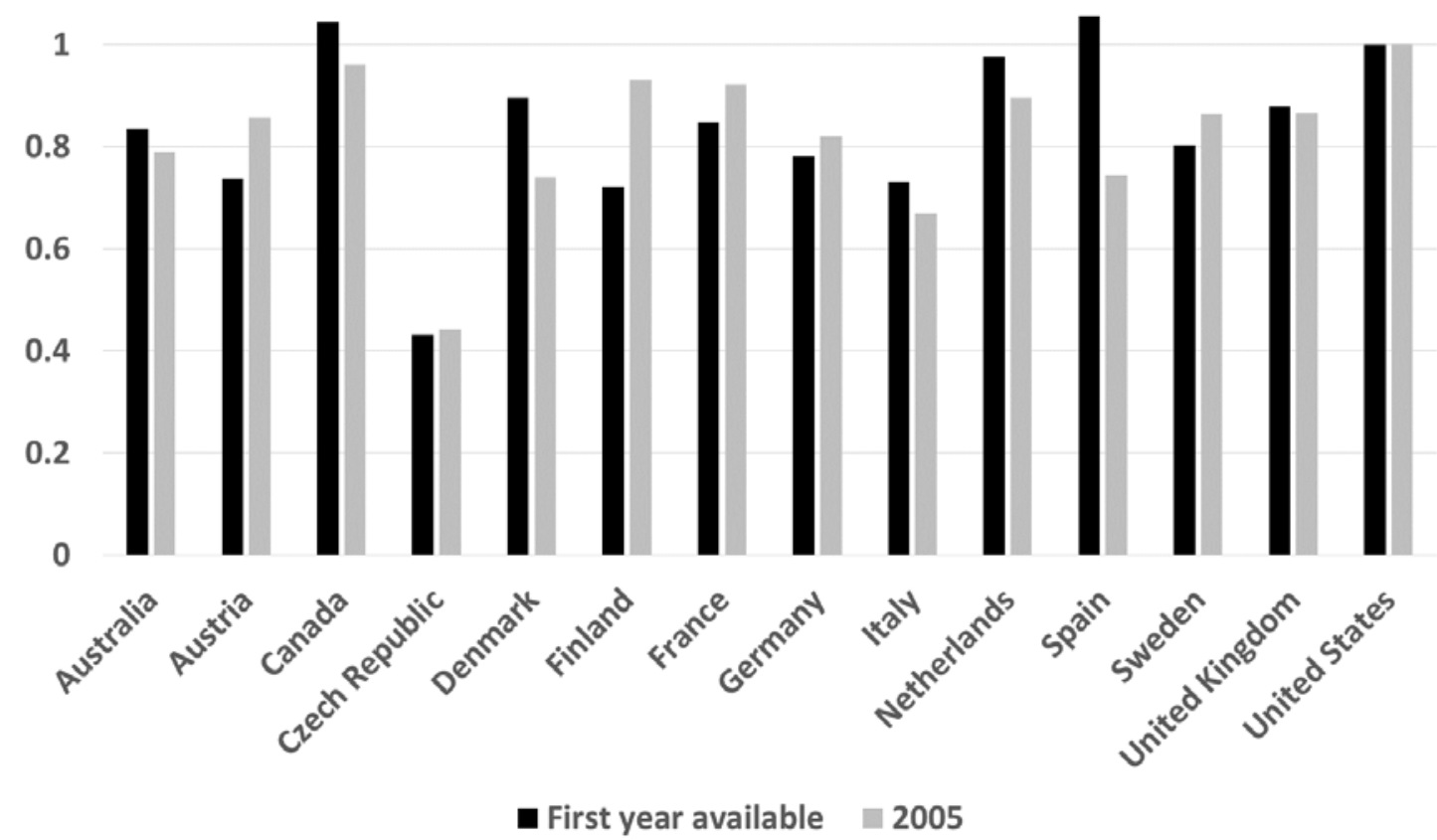

Note that between country comparisons for the first year available must be treated with caution because many industries are missing. 


\section{APPENDIX B: IMPACT INDICATORS ON WAGES}

Table B1 shows in column (1) the estimated impact of regulations on workers' rent per hour, like Table 1 column (3), and, column (2), the impact on real wages. The effects of regulations have the same sign in both columns: NMR - Entry and EPL - impact have positive and significant effects on workers' rent per hour and real wages, whereas NMR State has no significant impact. However, the effects on real wages are smaller than on workers' rent per hour. ${ }^{13}$

Table B1:

\begin{tabular}{l|ll}
\hline & $(1)$ & $(2)$ \\
\hline & Workers' rent & Real wage \\
& per hour & $\left(w / P^{P I B}\right)$ \\
Dep. var. (log) & $\left(w-w^{r}\right) / P^{P I B}$ & \\
& $(w)$ \\
& & \\
& & \\
NMR - Entry & $0.0510^{* * *}$ & $0.0159^{* * *}$ \\
& {$[0.0111]$} & {$[0.00394]$} \\
NMR - State & -0.00696 & -0.000384 \\
& {$[0.0100]$} & {$[0.00380]$} \\
EPL - impact & $0.375^{* * *}$ & $0.116^{* * *}$ \\
& {$[0.0950]$} & {$[0.0316]$} \\
Observations & 4,988 & 4,988 \\
R-squared & 0.981 & 0.997 \\
RMSE & 0.154 & 0.056 \\
\hline
\end{tabular}

Country*industry and country*year (separately for manufacturing and non-manufacturing industries) fixed effects.

Standard errors in brackets - *** $p<0.01,{ }^{* *} p<0.05,{ }^{*} p<0.1$.

13 The relationship between both is $\frac{w}{P^{P I B}}=\frac{w-w^{r}}{P^{P I B}} / \frac{w-w^{r}}{w}$ : when regulations increase workers' rent per hour, they also increase the share of rent in worker's wages so the increase in real wages is smaller. 


\section{APPENDIX C: FIRST STEP ESTIMATES OF TABLE 3 INSTRUMENTAL VARIABLE REGRESSION}

Section IV investigates relation (1) between OECD regulation indicators and our measures of the mark-up rate and worker's share of rent. The findings that NMR - Entry and NMR - State affect our measures but not EPL leads to the estimation strategy of relation (2) in section $\mathrm{V}$, i.e. the instrumental variable estimation of the impact of mark-up rate and worker's share of rent on TFP. The first stage specifications of this estimation differ from relation (1): (i) EPL - impact is omitted among the instruments; (ii) we introduce the product of the NMR - Entry and NMR - State indicators in order to increase first-stage explanatory power and to implement the over-identification Sargan test; (iii) relation (2) introduces the US TFP and the leads and lags of its first differences; and (iv) the estimation sample differs because of TFP data availability. Columns (1) and (2) of Table C1 show the estimation results of relation (1), as Table 1 columns (1) and (2), and columns (3) and (4) presents the first step estimates of the relation (2) instrumental variable estimation (whose estimates are presented in Table 3 column 6). Our main conclusion is that the estimated coefficients of the regulation indicators are very robust to the specification changes. The coefficient of US TFP is difficult to interpret - this variable is included in the estimated specification for methodological reasons. If we assume that US TFP takes into account technological changes, we would conclude that technological progress reduces the mark-up rate and increases worker's share of rent, maybe because technological change is a threat for dominant firms and requires qualified workers to be implemented. We can also observe that NMR - Entry and NMR - State variables have complementary effects on the mark-up rate and that this increase in rent mainly benefits firms. 
Table C1:

\begin{tabular}{|c|c|c|c|c|}
\hline & (1) & (2) & (3) & $(4)$ \\
\hline & \multicolumn{2}{|c|}{ Relation (1) estimation } & \multicolumn{2}{|c|}{$\begin{array}{l}\text { First step of relation (2) IV } \\
\text { estimation }\end{array}$} \\
\hline Dep. var. (log) & Mark-up rate & $\begin{array}{l}\text { Workers' share } \\
\text { of rent }\end{array}$ & Mark-up rate & $\begin{array}{l}\text { Workers' share } \\
\text { of rent }\end{array}$ \\
\hline US TFP (log), lagged & & & $\begin{array}{l}-0.0749 * * * \\
{[0.0126]}\end{array}$ & $\begin{array}{l}0.0232 * \\
{[0.0136]}\end{array}$ \\
\hline NMR - Entry & $\begin{array}{l}0.0516^{* * *} \\
{[0.0107]}\end{array}$ & $\begin{array}{l}0.0644 * * * \\
{[0.0105]}\end{array}$ & $\begin{array}{l}0.0459 * * * \\
{[0.00885]}\end{array}$ & $\begin{array}{l}0.0721 * * * \\
{[0.00958]}\end{array}$ \\
\hline NMR - State & $\begin{array}{l}0.0229 * * \\
{[0.0112]}\end{array}$ & $\begin{array}{l}0.00546 \\
{[0.0110]}\end{array}$ & $\begin{array}{l}0.0355^{* * *} \\
{[0.0101]}\end{array}$ & $\begin{array}{l}0.00628 \\
{[0.0109]}\end{array}$ \\
\hline $\begin{array}{l}\text { NMR - Entry * NMR - } \\
\text { State }^{(a)}\end{array}$ & & & $0.0102^{* * *}$ & $-0.0140 * * *$ \\
\hline EPL - Impact & $\begin{array}{l}0.0124 \\
{[0.0889]}\end{array}$ & $\begin{array}{l}-0.161 \\
{[0.103]}\end{array}$ & {$[0.00394]$} & {$[0.00427]$} \\
\hline Observations & 4,988 & 4,988 & 3,573 & 3,573 \\
\hline R-squared & 0.949 & 0.875 & 0.363 & 0.312 \\
\hline RMSE & 0.146 & 0.158 & 0.131 & 0.142 \\
\hline
\end{tabular}

Country*industry and country*year (separately for manufacturing and non-manufacturing industries) fixed effects.

Included standard errors in brackets - *** $p<0.01, * * p<0.05, * p<0.1$.

Leads and lags of US TFP (log) first differences included.

(a): The introduction of the NMR - Entry * NMR - State' variable into the estimated equations would lead to a problem of multicollinearity with NMR - Entry and NMR - State variables. To deal with this issue, we first regress this NMR - Entry * NMR - State' variable on all the other instruments and introduce the residual of this estimation into the estimated specifications in columns (3) and (4), rather than the observed NMR - Entry * NMR - State' values. Note that this choice has no effect on the estimates of the second step instrumental variable. 


\section{APPENDIX D: ANALYSIS OF SENSITIVITY TO CAPITAL INTENSITY}

Our measure of mark-up rate assumes capital is fixed in the short run and so does not take into account the user cost of capital. We may expect that this omission leads to the markup rate being overestimated. If regulations influence capital stock, this omission may lead to bias in our estimators. We therefore analyze the sensitivity of the relation (1) estimation results to the inclusion of the capital intensity among the control variables. Tables D1 and D2 take into account of this capital intensity and should be compare with Tables 1 and 2, respectively. Table D1, column (6), also shows the effects of regulations on capital intensity: the NMR - State and EPL - Impact variables affect capital intensity, but not NMR - Entry. This last result may be explained by the use of an aggregate capital stock, without taking into account capital composition, but such a breakdown would be beyond the scope of this paper (see Cette, Lopez and Mairesse, 2016b, for the importance of capital composition in the analysis of EPL effects). Most importantly, we observe that the effects of regulations on the mark-up rate, workers' share of rent and its components are robust to the inclusion of capital intensity among the control variables.

It is also interesting to note that capital intensity has a positive impact on the mark-up rate, as expected, but no significant effect on worker's share of rent. This last result corresponds to a strong positive effect of capital intensity on workers' rent per hour and a negative impact on rent per output unit offset by a negative impact on hours worked per output unit. The negative impact on workers' rent per hour is similar for the three skills levels, but the negative impact on hours worked per output unit is lower for highly-skilled workers, so their share of rent may increase with capital intensity.

Table D1: Impact of regulation indicators on capital intensity, mark-up and rent-sharing

\begin{tabular}{|c|c|c|c|c|c|c|}
\hline & (1) & $\begin{array}{l}(2)=(3)+(4)- \\
(5)\end{array}$ & (3) & (4) & (5) & (6) \\
\hline Dep. var. (log) & $\begin{array}{l}\text { Mark-up } \\
\text { rate }\end{array}$ & $\begin{array}{l}\text { Workers' } \\
\text { share of } \\
\text { rent }\end{array}$ & $\begin{array}{l}\text { Workers' } \\
\text { rent per } \\
\text { hour }\end{array}$ & $\begin{array}{l}\text { Hours } \\
\text { worked per } \\
\text { output unit }\end{array}$ & $\begin{array}{l}\text { Rent per } \\
\text { output unit }\end{array}$ & $\begin{array}{l}\text { Capital } \\
\text { intensity }\end{array}$ \\
\hline NMR - Entry & $\begin{array}{l}0.0511 \text { *** } \\
{[0.0108]}\end{array}$ & $\begin{array}{l}0.0644^{* * *} \\
{[0.0105]}\end{array}$ & $\begin{array}{l}0.0481 * * * \\
{[0.0115]}\end{array}$ & $\begin{array}{l}0.0787 * * * \\
{[0.0143]}\end{array}$ & $\begin{array}{l}0.0624 * * * \\
{[0.0116]}\end{array}$ & $\begin{array}{l}0.00783 \\
{[0.00689]}\end{array}$ \\
\hline NMR - State & $\begin{array}{l}0.0240 * * \\
{[0.0113]}\end{array}$ & $\begin{array}{l}0.00527 \\
{[0.0110]}\end{array}$ & $\begin{array}{l}-4.60 \mathrm{e}-05 \\
{[0.00998]}\end{array}$ & $\begin{array}{l}0.0323^{* *} \\
{[0.0145]}\end{array}$ & $\begin{array}{l}0.0270 * * \\
{[0.0118]}\end{array}$ & $\begin{array}{l}-0.0185^{* *} \\
{[0.00845]}\end{array}$ \\
\hline EPL - impact & $\begin{array}{l}0.00489 \\
{[0.0896]}\end{array}$ & $\begin{array}{l}-0.160 \\
{[0.104]}\end{array}$ & $\begin{array}{l}0.327 * * * \\
{[0.0913]}\end{array}$ & $\begin{array}{l}-0.715^{* * *} \\
{[0.0850]}\end{array}$ & $\begin{array}{l}-0.228^{* *} \\
{[0.0902]}\end{array}$ & $\begin{array}{l}0.130 * \\
{[0.0690]}\end{array}$ \\
\hline $\begin{array}{l}\text { Capital } \\
\text { intensity (log) }\end{array}$ & $\begin{array}{l}0.0579 * \\
{[0.0310]}\end{array}$ & $\begin{array}{l}-0.00997 \\
{[0.0358]}\end{array}$ & $\begin{array}{l}0.373^{* * *} \\
{[0.0432]}\end{array}$ & $\begin{array}{l}-0.550 * * * \\
{[0.0389]}\end{array}$ & $\begin{array}{l}-0.167 * * * \\
{[0.0451]}\end{array}$ & \\
\hline $\begin{array}{l}\text { Observations } \\
\text { R-squared } \\
\text { RMSE }\end{array}$ & $\begin{array}{l}4,988 \\
0.949 \\
0.146\end{array}$ & $\begin{array}{l}4,988 \\
0.875 \\
0.158\end{array}$ & $\begin{array}{l}4,988 \\
0.983 \\
0.149\end{array}$ & $\begin{array}{l}4,988 \\
0.982 \\
0.150\end{array}$ & $\begin{array}{l}4,988 \\
0.874 \\
0.172\end{array}$ & $\begin{array}{l}4,988 \\
0.986 \\
0.111\end{array}$ \\
\hline
\end{tabular}

Country*industry and country*year (separately for manufacturing and non-manufacturing industries) fixed effects.

Newey-West standard errors in brackets - *** $p<0.01$, ** $p<0.05, * p<0.1$. 
Table D2: Impact of regulation indicators by skills level

\begin{tabular}{|c|c|c|c|c|c|c|}
\hline & (1) & $(2)$ & (3) & (4) & (5) & $(6)$ \\
\hline Dep. var. (log) & \multicolumn{3}{|c|}{ Workers' rent per hour } & \multicolumn{3}{|c|}{ Hours worked per output unit } \\
\hline Skills & High & Medium & Low & High & Medium & Low \\
\hline NMR - Entry & $\begin{array}{l}0.0438^{* * *} \\
{[0.0159]}\end{array}$ & $\begin{array}{l}0.0448 * * * \\
{[0.0157]}\end{array}$ & $\begin{array}{l}0.0388^{* *} \\
{[0.0170]}\end{array}$ & $\begin{array}{l}0.0800^{* * *} \\
{[0.0134]}\end{array}$ & $\begin{array}{l}0.0842^{* * *} \\
{[0.0149]}\end{array}$ & $\begin{array}{l}0.0936^{* * *} \\
{[0.0165]}\end{array}$ \\
\hline NMR - State & $\begin{array}{l}-0.0233 \\
{[0.0158]}\end{array}$ & $\begin{array}{l}-0.0130 \\
{[0.0143]}\end{array}$ & $\begin{array}{l}0.0138 \\
{[0.0150]}\end{array}$ & $\begin{array}{l}-0.0235^{*} \\
{[0.0140]}\end{array}$ & $\begin{array}{l}0.0236 \\
{[0.0154]}\end{array}$ & $\begin{array}{l}0.0216 \\
{[0.0170]}\end{array}$ \\
\hline EPL - impact & $\begin{array}{l}0.0524 \\
{[0.130]}\end{array}$ & $\begin{array}{l}0.498^{* * *} \\
{[0.109]}\end{array}$ & $\begin{array}{l}0.481 * * * \\
{[0.154]}\end{array}$ & $\begin{array}{l}-0.243^{*} \\
{[0.132]}\end{array}$ & $\begin{array}{l}-0.748^{* * *} \\
{[0.0988]}\end{array}$ & $\begin{array}{l}-1.207 * * * \\
{[0.114]}\end{array}$ \\
\hline $\begin{array}{l}\text { Capital intensity } \\
(\log )\end{array}$ & $\begin{array}{l}0.370 * * * \\
{[0.0514]}\end{array}$ & $\begin{array}{l}0.360 * * * \\
{[0.0461]}\end{array}$ & $\begin{array}{l}0.360 * * * \\
{[0.0456]}\end{array}$ & $\begin{array}{l}-0.282^{* * *} \\
{[0.0494]}\end{array}$ & $\begin{array}{l}-0.583^{* * *} \\
{[0.0429]}\end{array}$ & $\begin{array}{l}-0.666^{* * *} \\
{[0.0433]}\end{array}$ \\
\hline $\begin{array}{l}\text { Observations } \\
\text { R-squared } \\
\text { RMSE }\end{array}$ & $\begin{array}{l}4,988 \\
0.983 \\
0.149\end{array}$ & $\begin{array}{l}4,988 \\
0.971 \\
0.207\end{array}$ & $\begin{array}{l}4,988 \\
0.978 \\
0.164\end{array}$ & $\begin{array}{l}4,988 \\
0.982 \\
0.150\end{array}$ & $\begin{array}{l}4,988 \\
0.984 \\
0.193\end{array}$ & $\begin{array}{l}4,988 \\
0.979 \\
0.165\end{array}$ \\
\hline
\end{tabular}

Country*industry and country*year (separately for manufacturing and non-manufacturing industries) fixed effects.

Newey-West standard errors in brackets - *** $p<0.01,{ }^{* *} p<0.05, * p<0.1$. 


\section{APPENDIX E: BREAKDOWN OF THE SIMULATION TFP GAINS BY REGULATED INDUSTRY}

In Section V, Chart 3 shows for each country the TFP gains expected from the adoption in 2013 of the lowest NMR - Entry and NMR - State indicator values, calculated according to our main estimates (given in Table 1, columns 1 and 2, and Table 3, column 6). In this appendix, Chart E1 shows the 2013 values of these OECD indicators in each regulated industry and Chart E2 the contribution of these industries to the TFP gains. These contributions depend on excess regulations and industry shares in value added. A major limitation of this assessment is that we use the same estimated average coefficient for each industry. Indeed, estimation of specific effects for each industry is not possible because of lack of data variability. We must bear this limitation in mind when we observe that in most countries the entry barriers (NMR - Entry) in 'Professional Services' and State control (NMR - State) in 'Retail Services' are the strongest contributors to expected TFP gains.

Chart E1: NMR indicators in 2013

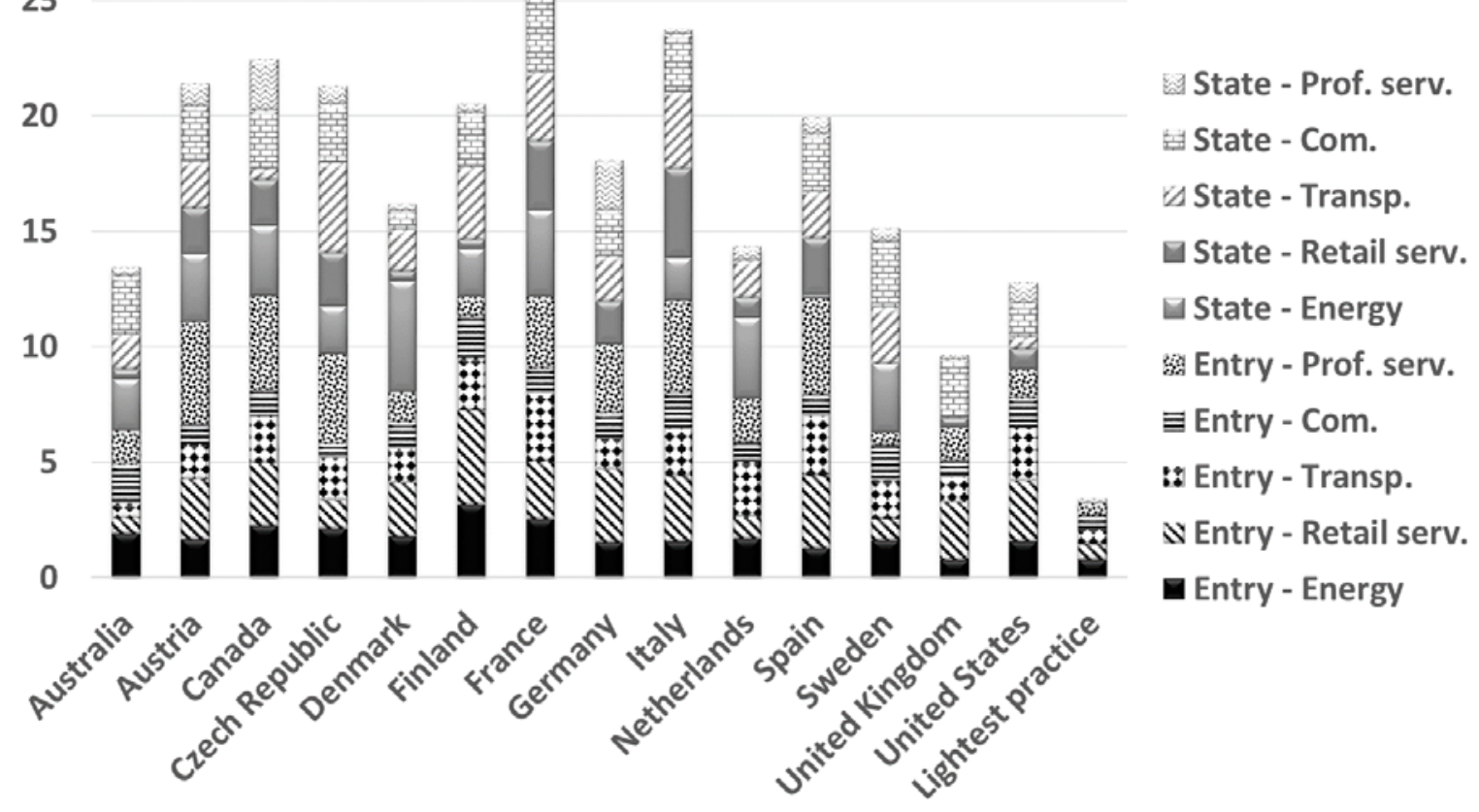


Chart E2: TFP gains from a switch to the lightest practices, by regulated industry

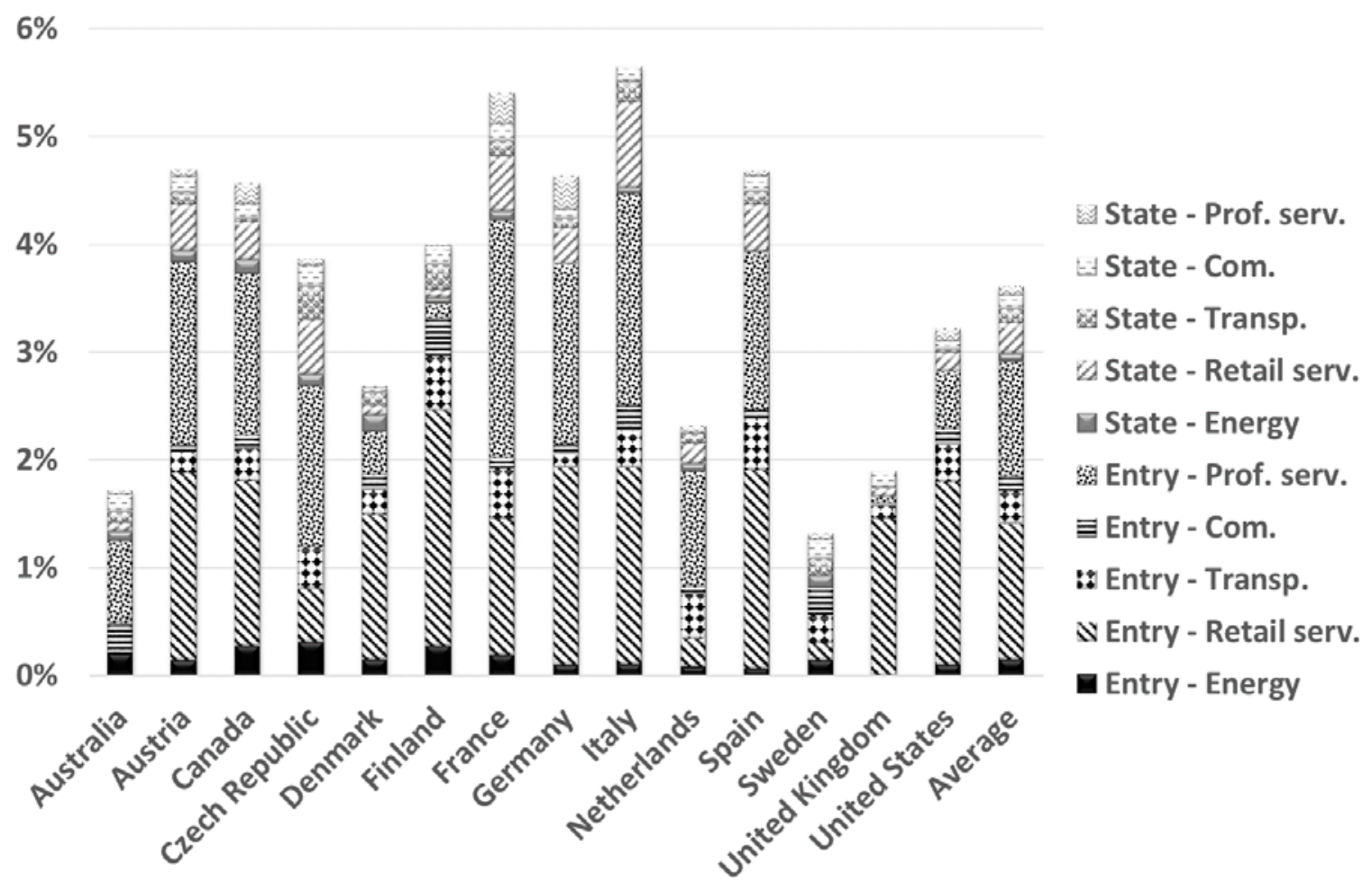

Source: authors' calculations using Table 1, col. 1 \& 2, and Table 3 col. 6. 